\title{
The Effect of Dual Language Activation on L2-Induced Changes in L1 Speech within a Code-Switched Paradigm
}

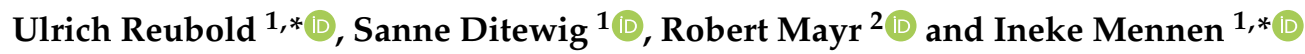 \\ 1 Department of English, University of Graz, 8010 Graz, Austria; sanne.ditewig@uni-graz.at \\ 2 Centre for Speech and Language Therapy and Hearing Science, Cardiff School of Health Sciences, \\ Cardiff Metropolitan University, Cardiff CF5 2YB, UK; rmayr@cardiffmet.ac.uk \\ * Correspondence: johann.reubold@uni-graz.at (U.R.); ineke.mennen@uni-graz.at (I.M.)
}

Citation: Reubold, Ulrich, Sanne Ditewig, Robert Mayr, and Ineke Mennen. 2021. The Effect of Dual Language Activation on L2-Induced Changes in L1 Speech within a Code-Switched Paradigm. Languages 6: 114. https://doi.org/10.3390/ languages6030114

Academic Editor: Elena Babatsouli

Received: 23 April 2021

Accepted: 25 June 2021

Published: 29 June 2021

Publisher's Note: MDPI stays neutral with regard to jurisdictional claims in published maps and institutional affiliations.

Copyright: (c) 2021 by the authors. Licensee MDPI, Basel, Switzerland. This article is an open access article distributed under the terms and conditions of the Creative Commons Attribution (CC BY) license (https:/ / creativecommons.org/licenses/by/ $4.0 /)$.

\begin{abstract}
The present study sought to examine the effect of dual language activation on L1 speech in late English-Austrian German sequential bilinguals, and to identify relevant predictor variables. To this end, we compared the English speech patterns of adult migrants to Austria in a code-switched and monolingual condition alongside those of monolingual native speakers in England in a monolingual condition. In the code-switched materials, German words containing target segments known to trigger cross-linguistic interaction in the two languages (i.e., [v-w], [ $\mathrm{t}(\mathrm{s})$-st $(\mathrm{x})]$ and [l-t]) were inserted into an English frame; monolingual materials comprised English words with the same segments. To examine whether the position of the German item affects L1 speech, the segments occurred either before the switch ("He wants a Wienerschnitzel") or after ("I like Würstel with mustard"). Critical acoustic measures of these segments revealed no differences between the groups in the monolingual condition, but significant L2-induced shifts in the bilinguals' L1 speech production in the codeswitched condition for some sounds. These were found to occur both before and after a code-switch, and exhibited a fair amount of individual variation. Only the amount of L2 use was found to be a significant predictor variable for shift size in code-switched compared with monolingual utterances, and only for $[w]$. These results have important implications for the role of dual activation in the speech of late sequential bilinguals.
\end{abstract}

Keywords: L1 attrition; speech; code-switching; English; Austrian German; phonetic drift

\section{Introduction}

It is now widely accepted that late sequential bilinguals who are being immersed in a second language (L2) environment long-term may experience a change in linguistic abilities in their native language, a phenomenon commonly referred to as first language (L1) attrition (Köpke and Schmid 2004). While the majority of L1 attrition studies have focused on linguistic levels such as syntax, morphology, and the lexicon (Schmid 2002), recent years have seen a proliferation of research on phonetic and phonological attrition. So far, studies evidenced changes to the L1 in both segmental (Bergmann et al. 2016; de Leeuw et al. 2013; de Leeuw et al. 2018b; de Leeuw 2019a; Guion 2003; Flege 1987; Kornder and Mennen 2021; Major 1992; Mayr et al. 2012; Stoehr et al. 2017; Ulbrich and Ordin 2014) and prosodic (de Leeuw et al. 2012; Mennen and Chousi 2018) areas of L1 production. While the above studies provide evidence for phonetic attrition, changes in L1 phonology have also been reported, resulting in, for instance, a neutralization of phonological contrasts (Cho and Lee 2016; de Leeuw et al. 2018a; Dmitrieva et al. 2010) or a change in L1-specific prominence patterns in anaphora resolution (Gargiulo and Tronnier 2020). Moreover, a few studies have shown that attrition can also affect the perception of segments (Ahn et al. 2017; Celata and Cancila 2010; Dmitrieva 2019), and that native listeners' global foreign accent ratings may be influenced by long-term immersion in an L2 environment (Major 2010). Evidence of L2-induced changes to L1 pronunciation has not only been observed in long-term residents in an L2 environment, but has also been found 
to affect relatively inexperienced L2 learners with little or short-term exposure to the L2 (Chang 2012, 2013, 2019; Dmitrieva et al. 2020; Kartushina et al. 2016) or whose linguistic environment regularly changes by travelling between the L1- and L2-speaking countries (Sancier and Fowler 1997; Tobin et al. 2017). This type of change is, however, typically referred to as "gestural drift" (Sancier and Fowler 1997) or "phonetic drift" (Chang 2012, 2013) rather than L1 attrition, because of the temporary or transient nature of the change.

The changes to L1 pronunciation reported in the literature appear to take the form of either assimilation or dissimilation patterns. Assimilation refers to a shift of the L1 sound in the direction of the L2 sound, resulting in a complete or intermediate merging of L1 and L2 categories (e.g., Alharbi et al. forthcoming; de Leeuw et al. 2013; Flege 1987; Flege and Hillenbrand 1984; Major 1992; Mayr et al. 2012; Ulbrich and Ordin 2014). Dissimilation or polarization refers to a shift of the L1 sound away from both L1 and L2 norms, resulting from "overshooting" the L1 norm (Flege and Eefting 1987; de Leeuw et al. 2012). According to the Speech Learning Model (SLM) (Flege 1995; Flege and Bohn 2021), which has been adopted in a number of previous studies on L1 attrition of speech (Mayr et al. 2012; Bergmann et al. 2016; de Leeuw et al. 2018a; de Leeuw et al. 2018b; Mayr et al. 2020), these assimilation and dissimilation effects arise because L1 and L2 phonetic categories exist in a common phonetic space, and are, therefore, likely to influence one another. Assimilation results from the learners' inability to discern phonetic differences between L1 and L2 sounds, which "may cause the L1 sound to shift toward (assimilate to) the L2 sound in phonetic space" (Flege and Bohn 2021, p. 42). Dissimilation, on the other hand, is caused by the need "to maintain phonetic contrast between certain pairs of L1 and L2 sounds" (Flege and Bohn 2021, p. 39). While the studies outlined above show that both patterns can occur in L1 attrition of speech, dissimilation patterns are less commonly reported than assimilation patterns (so far, only in Flege and Eefting 1987 and de Leeuw et al. 2012).

The present study aims to contribute to the growing body of work on L2-induced changes to L1 speech production in late sequential bilinguals residing in an L2-speaking environment by acoustically examining a number of segments produced by a group of L1 speakers of Standard Southern British English (SSBE) who have emigrated to Austria in adulthood and have (Austrian) German as their L2.

\subsection{The Scale of L1 Attrition of Speech}

The steadily increasing body of evidence outlined above suggests that the observed changes to L1 pronunciation are not limited to a few isolated cases but are widespread and pervasive (de Leeuw 2019b; Mayr et al. 2020). Nevertheless, the documented changes are unlikely to represent the full scale of L1 attrition in the phonetic/phonological domain, as only limited features have been investigated so far, with a focus on temporal (e.g., Alharbi et al. forthcoming; Flege 1987; Kornder and Mennen 2021; Major 1992; Mayr et al. 2012; Stoehr et al. 2017) and spectral aspects (e.g., de Leeuw et al. 2013; de Leeuw 2019a; Ulbrich and Ordin 2014) of consonant production, and spectral and/or durational aspects of vowel production (e.g., Bergmann et al. 2016; de Leeuw 2019a; Guion 2003; Kornder and Mennen 2021; Mayr et al. 2012). Furthermore, evidence is emerging that not all phonetic aspects are vulnerable to attrition. For instance, in a study of two Dutch monozygotic twin sisters, one of whom moved to the UK in adulthood (Mayr et al. 2012), pervasive changes were found in the L1 (Dutch) voiceless plosives produced by the sister who was immersed in the English-speaking environment, whereas no such effects were found in her productions of the Dutch voiced plosives. Similarly, while extensive attrition was found in her production of Dutch vowels, no evidence of attrition was found in her production of the Dutch /a/. Likewise, Stoehr et al. (2017), in a study of Dutch-German late sequential bilinguals, found evidence of L1 attrition in the Dutch voiceless plosives, whereas the same participants were able to maintain native levels of prevoicing in voiced plosives. Finally, Bergmann et al. (2016) found evidence of L1 attrition in the formant frequencies for /a:/ and /1/, but not for / $\varepsilon /$ and / $/$ in their study of L1 German immigrants to Canada and the US. 
This suggests that not all segments are equally prone to L1 attrition. In order to establish whether some areas of pronunciation are indeed more susceptible to attrition than others, one would need to compare a range of areas of pronunciation within the same group of individuals. Studies examining more than one sound class are, however, rare (but see Bergmann et al. 2016; de Leeuw 2019a; Kornder and Mennen 2021; Mayr et al. 2012).

\subsection{Individual Variation and the Role of L1 Use and Dual Language Activation}

While it is clear that L1 speech may undergo attrition, research has also shown that changes to L1 speech are only evident in some, but not all, late sequential bilinguals residing in an L2-speaking environment. For instance, in Major's (1992) study of voice onset time in voiceless plosives, one out of five of the English-Portuguese bilinguals produced the plosives entirely natively in both languages, thus showing no evidence of L1 attrition. Similarly, only three of the ten Albanian-English bilinguals in de Leeuw et al. (2018a) were found to suffer from attrition, by neutralizing or partially neutralizing the contrast between dark and light laterals, while the other seven participants showed no sign of attrition. Likewise, de Leeuw et al. (2013) report that, in a group of ten German-English late bilinguals, nine exhibited variable degrees of changes to their L1 tonal alignment patterns, but one participant produced tonal alignment values that were entirely within the norms of monolingual speakers of either language. These results suggest that not every late sequential bilingual immersed in an L2 environment is affected by phonetic attrition and that there is a fair amount of interpersonal variation in the degree of attrition evidenced in production studies. There is also notable variation in the number of perceived attriters in global foreign accent rating studies, with reported figures ranging from $25 \%$ (de Leeuw et al. 2010) to $40 \%$ (Bergmann et al. 2016) of the investigated migrant population.

In order to reach a better understanding of the nature of L1 attrition, it is necessary to establish which factors drive the attrition process and lead to apparent changes in the pronunciation of some individuals but not others. While there is a fairly good understanding of the factors that contribute to individual differences in how well L2 learners are able to produce L2 speech, there has been little attempt to establish the variables that predict which individuals are more likely to undergo changes in L1 speech. It is often assumed that some variables-such as an increase in exposure to and use of the L2, as well as a reduction in L1 use associated with L2 immersion (see Dmitrieva et al. 2020)—may be important; however, the role of various predictor variables is rarely systematically investigated. The only studies that have tested predictor variables in L1 speech attrition have investigated their impact on global foreign accent ratings (de Leeuw et al. 2010; Hopp and Schmid 2013) and the limited findings so far remain inconclusive. Hopp and Schmid (2013) tested the influence of age of emigration, length of residence in an L2 environment, amount of L1 and L2 use, and L2 proficiency on global foreign accent ratings in L1 attriters. None of the tested factors were found to predict the degree of perceived foreign accent in the L1. However, in their study on German immigrants to the Netherlands and Anglophone Canada, de Leeuw et al. (2010) found that of the three variables tested (language use, age of arrival in the host country, length of residence in the host country), only language use predicted the perceived degree of foreign accent, while the other two factors were not found to play a role. Bilinguals were more often perceived as non-native in their L1 if they used their L1 in situations where they were likely to code-switch (such as in conversations with family members or friends). The bilinguals who used German in situations where code-switching was unlikely to occur (such as in work settings or conversations with monolingual speakers of the L1) were more likely to be perceived as native speakers of their L1. This suggests that situations where contact with the L1 predominantly takes place in a setting where only the L1 is used may protect against changes in L1 pronunciation; conversely, L1 contact in a situation where bilinguals regularly use both languages may facilitate L1 speech attrition (de Leeuw et al. 2010).

While effects of language use on L1 speech attrition have also been documented in other studies (e.g., Stoehr et al. 2017; Chang 2019), the particular language use situation 
referred to in de Leeuw et al. (2010) is one which requires sustained co-activation of the L1 and L2. Although both languages of a bilingual are always activated to some extent, the degree of activation can range from full activation of both languages, referred to as a bilingual language mode, to inhibition of one of the bilingual's languages in a monolingual language mode (Grosjean 2001). In contexts of dual language activation, and particularly so in code-switching where both languages need to be active, continued cross-linguistic interaction is commonly observed (e.g., Green 1998; Van Hell and Dijkstra 2002). In de Leeuw et al.'s (2010) study, the dual activation of both languages during the bilinguals' L1 contact, resulting from high levels of code-switching, led to them being perceived as less native in their L1. Mayr et al. (2020), in a study of Spanish language teachers and nonteachers residing in the UK, aimed to differentiate the effects of L1 use and dual language activation in the perceived attrition of L1 speech. It was argued that when teaching their L1 in an L2-speaking environment, language teachers are unlikely to be able to inhibit one of their languages to the extent that non-teachers are able to do. While non-teachers may activate their L2 predominantly at work and their L1 at home, the specific demands on language teachers in foreign language classroom settings will inevitably lead to dual language activation during teachers' professional activities. By investigating two groups of Spanish speakers, teachers and non-teachers, who differed in their need to co-activate their languages in professional settings, but had similar levels of L1 use, Mayr et al. (2020) were able to separate the two possible effects. Their results showed that the group of Spanish language teachers were perceived as less native in their L1 than the group of non-teachers, whereas low L1 use had no effect on the perceived L1 accent. This suggests that bilinguals who are often in situations that lead to cross-linguistic interaction, such as L1 contact where code-switching is common, may be more prone to attrition than bilinguals who "function in alternate monolingual language modes", and reduced L1 use in itself is likely to play less of a role in L1 attrition of speech (Mayr et al. 2020, p. 14).

\subsection{Code-Switching and Its Effect on L1 Speech Production}

Despite the suggestions in the literature that dual language activation and its resulting cross-linguistic interaction may play a role in L1 attrition of speech, few studies have addressed how it influences L1 speech production. Past studies of L1 attrition of speech have investigated the effects on the L1 predominantly within monolingual language modes (Grosjean 2001), where bilinguals' two languages are carefully separated to avoid dual language activation, and interaction between the two languages is less likely to occur. Comparatively little research has investigated phonetic interaction in situations where both languages are maximally activated - such as in code-switched speech-a situation which is thought to serve "as a catalyst for interaction" (Olson 2013, p. 410). Yet, code-switched speech provides an interesting context in which to examine L1 attrition of speech, as it offers an opportunity to maximize the number and types of possible changes that can occur in L1 speech attrition, whereas speech produced in a non-code-switched context is much less likely to result in cross-language interaction. When the two languages are maximally activated, the full extent of language interaction should become visible, allowing for an examination of the relative susceptibility of different areas of pronunciation to L1 attrition.

So far, however, the majority of studies on the effect of code-switching on speech production have focused on investigations of early bilinguals in languages in contact research. On the one hand, there are some reporting unidirectional transfer with Language A changing towards Language B, but not the reverse, including L1-to-L2 transfer (Antoniou et al. 2011; Bullock et al. 2006; Goldrick et al. 2014; Muldner et al. 2019) and L2-to-L1 transfer (Olson 2013). Other studies exhibit bidirectional transfer, with Language A changing towards Language B and Language B changing towards Language A (Balukas and Koops 2015; Bullock and Toribio 2009; Piccinini and Arvaniti 2015), or no effect of code-switching (Grosjean and Miller 1994; López 2012). The focus of these studies has been almost exclusively on the production of voice onset time in plosives (but see Muldner et al. 2019; Olson 2012). There are as yet very few studies that have investigated the effects of 
code-switching on the L1 speech of late sequential bilinguals who are being long-term immersed in an L2 environment, and findings have so far been contradictory. Bullock and Toribio (2009) report asymmetrical effects in the L1 production of voice onset times (VOT), with VOT affected in the English-Spanish bilinguals' L1, but not in the L1 of the Spanish-English bilinguals. Olson (2013), however, found consistent L2-to-L1 effects in VOT production by both Spanish-English and English-Spanish late sequential bilinguals. Neither Bullock and Toribio (2009) nor Olson (2013) reported differences in the relative susceptibility of the segments under investigation, but this is perhaps not surprising, given that they only examined plosives. Moreover, none of the studies investigated which factors may have resulted in L1 attrition occurring in some (groups of) bilinguals but not others. A final point of interest is whether the influence of a switch is more evident and/or more frequent in anticipation of the switch or following the switch. So far, only Bullock and Toribio (2009) examined whether the effect of code-switching on production is influenced by the position of the switch. Their results show that the observed changes in the L1 of the English-Spanish and Spanish-English late sequential bilinguals only occurred in anticipation of a switch, and no changes were observed in L1 VOT productions following a switch. This suggests that the direction of L2-induced influences may play a role in the occurrence of L1 speech changes, in that segments occurring before a switch may be more prone to changes than those after a switch. However, more research is needed to confirm or reject this hypothesis.

\subsection{The Current Study}

The current study investigated L1 speech attrition within a context of dual language activation using a code-switched paradigm in which a bilingual's two languages are thought to be maximally activated and high levels of language interaction are expected to occur (Green 1998; Olson 2013). The study compares a number of L1 segments, in switched and non-switched conditions, produced by a group of late English-Austrian German (henceforth: English-Austrian) sequential bilinguals, all native speakers of SSBE who emigrated to Austria in adulthood and have (Austrian) German as their L2. This allows us to determine whether some segments are more prone to L2-induced changes in L1 speech than others, and whether this is more evident-as suggested by previous research -in a context of dual language activation than in a monolingual language mode where one of the languages is more likely to be inhibited (de Leeuw et al. 2010; Mayr et al. 2020). The experimental design of the study, in which German words containing segments expected to trigger transfer are inserted into an English frame, and corresponding English segments occur both before and after the German word, also allows us to address whether the L2-induced phonetic influences on L1 production are progressive or regressive. A final objective of this study is to test the influence of a number of predictor variables (i.e., age of emigration, length of residence in an L2 environment, relative amount and quality of L1 and L2 use, and L2 proficiency) on the degree of L1 attrition, with the aim of identifying which predictor variables govern L1 attrition and explaining why L1 attrition occurs in some individuals but not others.

\section{Materials and Methods}

\subsection{Participants}

We recruited a group of late sequential bilinguals (BIL, $N=25,11$ females, 14 males) who were raised monolingually in the southeast of England as speakers of SSBE and moved to Austria as adults. The speakers in this group were all long-term residents in Austria and lived there continuously for a minimum of two years. The participants were recruited via existing contacts, as well as expatriate communities, language schools, and the British Embassy in Vienna. The age of the participants ranged from 24 to 71 years, with a mean age of 44.8 years. None of the participants reported daily use of foreign languages other than German. In addition, a small group of monolingual speakers of SSBE residing in the UK were recruited for the study (MON, $N=10,6$ female, 4 male). The monolingual 
speakers had never lived outside England and reported no more than high school level knowledge of other languages. Participants in both groups were educated to a tertiary level. The age of the MON participants ranged from 21 to 56 years, with a mean age of 29.6 years. For all speakers in each group, we obtained informed consent before participation, and all participants were offered compensation for their time. None of the participants reported any known speech, language, or hearing impairments.

For the BIL group, we collected some background information about the participants' language use through an online questionnaire. The questionnaire was adapted from Schmid (2011) to the situation of our participant group, and focused on variables that may predict L2-induced changes to L1 speech (e.g., de Leeuw et al. 2010; Hopp and Schmid 2013). These were AoE (age of emigration to Austria), LoR (length of residence in Austria), L2 proficiency, amount of contact with English in a setting in which language mixing was either likely or not likely, amount of L1 use, and amount of L2 use. Participants were specifically targeted such that they varied in age of emigration (AoE) and length of residence (LoR) in Austria, in order to test the effect of these variables on possible L2-induced changes to L1 speech. The speakers' AoE in Austria varied between 21 and 58 years (mean: 33.5), and their LoR in Austria ranged from 2 to 37 years (mean: 11.5).

Following de Leeuw et al. (2010), the type of contact with the L1 was divided into what was termed $\mathrm{C}+\mathrm{M}$ (L1 contact in settings where language mixing is likely to occur) and $\mathrm{C}-\mathrm{M}$ (L1 contact in settings where language mixing is unlikely to occur). The variable $\mathrm{C}+\mathrm{M}$ describes informal types of L1 contact, i.e., with family and friends residing in Austria, ${ }^{1}$ whereas $\mathrm{C}-\mathrm{M}$ describes contact with monolingual L1 speakers as well as more formal types of contact (i.e., through work). As in de Leeuw et al. (2010), the two contact variables consisted of the means of answers to a number of questions. The answers to the questions were all expressed on a 5-point Likert scale, which was converted to a scale of $0-1$, where 0 refers to the minimum and 1 to the maximum amount of contact, in order to compare our results to those in de Leeuw et al. (2010). The variables "amount of L1 use", "amount of L2 use" and "L2-proficiency" also consisted of answers to a number of questions using 3 to 6-point Likert scales and were also converted on a scale from 0 to 1 . The variable "amount of L1 use" refers to the use of and exposure to the L1 with native speakers living in the UK. The variable "amount of L2 use" refers to the use of and exposure to the L2 with native Austrian speakers. The variable "L2 proficiency" refers to self-reported proficiency in pronunciation, fluency, oral comprehension, writing and reading. Scores for each variable are displayed in Table 1 . The scores for $\mathrm{C}-\mathrm{M}$ ranged from 0.31 to 0.94 , for $\mathrm{C}+\mathrm{M}$ from 0.38 to 0.92 , for L1 use from 0.17 to 1 , for L2 use from 0.18 to 0.97 , and for L2 proficiency from 0.20 to 0.96 .

Table 1. Background details: bilingual participants.

\begin{tabular}{ccccccccc}
\hline Participant & Gender & $\begin{array}{c}\text { AoE } \\
\text { (yrs) }\end{array}$ & $\begin{array}{c}\text { LoR } \\
\text { (yrs) }\end{array}$ & C+M & C-M & L1 Use & L2 Use & $\begin{array}{c}\text { L2 } \\
\text { Proficiency }\end{array}$ \\
\hline BIL001 & F & 28 & 21 & 0.75 & 0.59 & 0.75 & 0.71 & 0.76 \\
BIL002 & M & 31 & 14 & 0.56 & 0.86 & 0.92 & 0.46 & 0.72 \\
BIL003 & M & 34 & 20 & 0.63 & 0.61 & 0.17 & 0.50 & 0.40 \\
BIL004 & F & 58 & 2 & 0.88 & 0.50 & 0.63 & 0.39 & 0.68 \\
BIL005 & M & 23 & 16 & 0.64 & 0.67 & 0.50 & 0.71 & 0.80 \\
BIL006 & M & 39 & 16 & 0.80 & 0.72 & 0.71 & 0.44 & 0.44 \\
BIL007 & F & 22 & 32 & 0.50 & 0.72 & 0.58 & 0.83 & 0.96 \\
BIL008 & M & 31 & 30 & 0.47 & 0.58 & 0.25 & 0.97 & 0.52 \\
BIL009 & M & 34 & 37 & 0.31 & 0.38 & 0.50 & 0.96 & 0.84 \\
BIL010 & M & 29 & 3 & 0.63 & 0.50 & 0.35 & 0.60 & 0.36 \\
BIL012 & F & 52 & 6 & 0.81 & 0.79 & 0.67 & 0.46 & 0.20 \\
BIL014 & M & 39 & 3 & 0.69 & 0.84 & 0.75 & 0.36 & 0.44 \\
BIL015 & F & 23 & 13 & 0.44 & 0.78 & 0.42 & 0.49 & 0.92 \\
BIL016 & M & 24 & 11 & 0.50 & 0.78 & 0.92 & 0.69 & 0.60 \\
\hline
\end{tabular}


Table 1. Cont.

\begin{tabular}{ccccccccc}
\hline Participant & Gender & $\begin{array}{c}\text { AoE } \\
\text { (yrs) }\end{array}$ & $\begin{array}{c}\text { LoR } \\
\text { (yrs) }\end{array}$ & C+M & C-M & L1 Use & L2 Use & $\begin{array}{c}\text { L2 } \\
\text { Proficiency }\end{array}$ \\
\hline BIL017 & F & 22 & 2 & 0.81 & 0.69 & 0.92 & 0.69 & 0.84 \\
BIL018 & M & 29 & 3 & 0.69 & 0.75 & 0.25 & 0.71 & 0.60 \\
BIL019 & M & 21 & 12 & 0.75 & 0.84 & 0.63 & 0.68 & 0.52 \\
BIL021 & F & 30 & 8 & 0.86 & 0.67 & 0.67 & 0.70 & 0.36 \\
BIL025 & M & 43 & 13 & 0.80 & 0.59 & 0.63 & 0.52 & 0.44 \\
BIL027 & F & 34 & 2 & 0.80 & 0.69 & 0.92 & 0.18 & 0.20 \\
BIL028 & M & 56 & 11 & 0.86 & 0.75 & 1.00 & 0.54 & 0.64 \\
BIL029 & F & 44 & 4 & 0.89 & 0.75 & 0.88 & 0.67 & 0.40 \\
BIL030 & M & 29 & 3 & 0.63 & 0.67 & 0.75 & 0.69 & 0.48 \\
BIL031 & F & 44 & 2 & 0.94 & 0.78 & 0.54 & 0.57 & 0.52 \\
BIL032 & F & 24 & 3 & 0.84 & 0.92 & 0.75 & 0.27 & 0.24 \\
\hline
\end{tabular}

Note: $\mathrm{AoE}=$ age of emigration, $\mathrm{LoR}=$ length of residence; $\mathrm{C}+\mathrm{M}=\mathrm{L} 1$ contact in settings where language mixing is likely to occur; $\mathrm{C}-\mathrm{M}=\mathrm{L} 1$ contact in settings where language mixing is unlikely to occur; the scores for $\mathrm{C}+\mathrm{M}$, $\mathrm{C}-\mathrm{M}, \mathrm{L} 1 \mathrm{use}, \mathrm{L} 2 \mathrm{use}$, and L2 proficiency are on a scale from 0 to 1 , where 0 refers to the minimum amount of contact, use, or proficiency and 1 to the maximum amount. As data come from a larger project, the numbering of participants is not continuous.

The participants mostly reported having been taught Standard Austrian German (SAG) during German languages classes whilst residing in Austria (Moosmüller et al. 2015). Moreover, it is likely that they will have also had exposure to a range of different social and regional forms of German as spoken in Austria. However, while this was not formally assessed, in view of their high education levels, they are likely to have oriented towards standard accentual features.

\subsection{Speech Materials and Recordings}

Regulations concerning contact during the COVID-19 pandemic required the implementation of alternative means of data collection. Therefore, despite concerns about technical issues with remote recordings conducted via online tools (cf. Sanker et al. 2021), we decided to use WikiSpeech. ${ }^{2}$ This is a content management system for the web-based creation of speech databases (Draxler and Jänsch 2008) and allows for unsupervised online recordings and a project administration workflow, such as the editing of speech content and data download on the part of the project administrator. Participants received stepby-step instructions. They were asked to read aloud the items presented on their screen and to record themselves using either built-in microphones or headsets and to avoid noisy environments. Participants were also asked to adjust recording levels and to listen to the first few test items, in order to avoid poor audio recording quality. All items were recorded in random order and included two repetitions each. There was an automatic pause of $1.5 \mathrm{~s}$ between the presentation of individual stimuli. Participants also had the opportunity to pause the recording session at any time and resume the process at a later point, but were advised to finish a recording session within one sitting. The recordings were checked carefully for their recording quality and, on occasion, participants were asked to re-record certain items containing sound quality issues or reading errors.

The recorded items consisted of materials for the study reported here, interspersed with a larger set of materials devised to test for potential segmental and prosodic changes to L1 speech, which will be reported elsewhere. The entire set consisted of 313 items and took each participant approximately $60 \mathrm{~min}$ to record. Of those, all 43 items with our target segments $(\times 2$ repetitions $=86)$ form part of the current experiment. These comprise two sets: (i) a set of code-switched (CS) materials (recorded by the BIL group only) and (ii) a set of non-CS materials (recorded by both the BIL and MON group). The CS materials consist of 15 sentences, each repeated twice, in an L1 (English) frame in which German items were inserted, containing the following segments, henceforth referred to as sound pairs: $<\mathrm{w}>[\mathrm{v}-\mathrm{w}],<\mathrm{st}(\mathrm{r})>\left[\int \mathrm{ft}(\mathrm{r})-\mathrm{st}(\mathrm{x})\right]_{;}^{3}<\mathrm{l}>[\mathrm{l}-\mathrm{t}]$. These were carefully selected based on known cross-linguistic differences between English and German (Kufner 1971; Moulton 
1962) and evidence from L2 learning contexts (e.g., Hickey 2020). Each sound pair consists of an English consonant or consonant cluster with a phonetically similar "counterpart" in German, which, in turn, was expected to trigger L2-to-L1 transfer. Specifically, we anticipated that English [ 1 ] would become lighter under the influence of L2 German [1]. Similarly, the production of English [w] was expected to be realized in approximation of the labiodental fricative [v], a category that is shared by English and German, but only used for the pronunciation of the grapheme $<w>$ in German. Finally, we predicted that English [st] and [st. $]$ would approximate the realization of L2 German [jt] and [jt $\mathrm{t}]$, respectively.

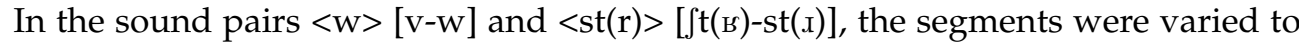
occur either before or after the German item, to determine whether any observed L2-induced influences are progressive or regressive: e.g., <st> [jt-st]: "She walked to Stadteck station" (progressive), or "They stayed at Stiftung" (regressive). For the sound pair $<\mathrm{l}>[1-\mathrm{l}]$, we only had sentences for the progressive environment. However, after an analysis of the transfer direction for the sound pairs $\langle\mathrm{W}>[\mathrm{v}-\mathrm{w}]$ and $\langle\mathrm{st}(\mathrm{r})>[\mathrm{Jt}(\mathrm{B})]-[\mathrm{st}(\mathrm{I})]$ showed no significant main effect nor an interaction with other factors (see below in Results Sections 3.1.2 and 3.2.2), we decided to add the sound pair $<\mathrm{l}>[1-\mathrm{l}]$. Table 2 illustrates the sentences that were used to elicit the sound pairs in this study, along with the number of progressive and regressive items analyzed. A total of 834 items from the set of CS materials were analyzed, consisting of 206 [w] tokens, 461 [s] tokens (adjacent to [t] or [t $\mathrm{t}]$ ), and 167 [t] tokens.

Table 2. Code-switching materials analyzed in this study.

\begin{tabular}{|c|c|c|c|}
\hline Sound Pair & $\begin{array}{l}\text { Direction of Expected } \\
\text { L2-Induced Change }\end{array}$ & $N$ & Sentence \\
\hline \multirow[t]{4}{*}{$<\mathrm{w}>[\mathrm{v}-\mathrm{w}]$} & Progressive & 100 & $\begin{array}{l}\text { (a) I like Würstel with mustard. } \\
\text { (['vypstl wıð]) }\end{array}$ \\
\hline & & & $\begin{array}{l}\text { (b) There's a Wienerwald }{ }^{1} \text { where I live. } \\
\left.\text { (['vi:nevalt }{ }^{\text {h }} \text { weəə⿱一土 }\right] \text { ) }\end{array}$ \\
\hline & Regressive & 106 & $\begin{array}{l}\text { (a) He wants a Wienerschnitzel. } \\
\text { ([wonts ə 'vi:nefnitsl]) }\end{array}$ \\
\hline & & & $\begin{array}{l}\text { (b) He went to Weiz at a fast pace. } \\
\text { ([went }{ }^{\mathrm{h}} \mathrm{t}^{\mathrm{h}} \text { } \partial \text { varts]) }\end{array}$ \\
\hline \multirow[t]{2}{*}{$<\mathrm{st}(\mathrm{r})>\left[\int \mathrm{t} \mathrm{t}\right]-[\mathrm{sts}]$} & Progressive & 243 & 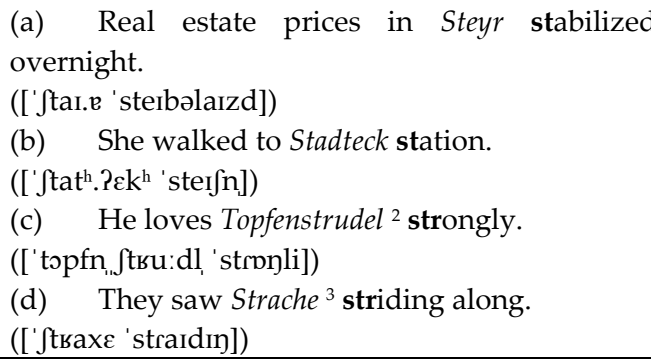 \\
\hline & Regressive & 218 & 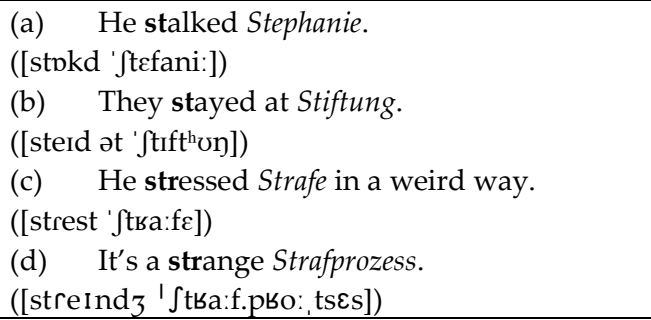 \\
\hline$<\mathrm{l}>[1-\mathrm{l}]$ & Progressive & 167 & 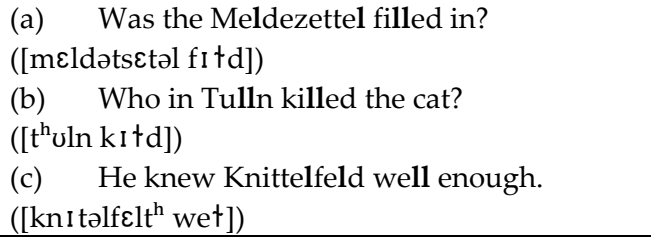 \\
\hline
\end{tabular}

${ }^{1}$ Wienerwald refers to the name of a well-known chain of fast-food restaurants. ${ }^{2}$ Topfenstrudel was chosen instead of Strudel in order to avoid confusion with the English word strudel. ${ }^{3}$ Strache is the surname of a well-known Austrian politician. 
The set of non-CS materials (which were recorded for both the BIL and MON group) consisted of 28 words repeated twice (see Table 3), starting with the sounds that form the sound pairs in the CS materials, i.e., [w, v, s, $\left.\int, 1,1\right]$. These words had been recorded with two repetitions, one each embedded within the carrier sentences "Say TARGETWORD again" and "We said TARGETWORD together", respectively. A total of 1867 tokens were extracted from the recordings of the BIL and MON speakers for further analysis. Table 3 shows the number of words that were analyzed for each sound and group.

Table 3. Set of non-CS materials.

\begin{tabular}{cccc}
\hline Speech Sound & Target Words & N (MON) & N (BIL) \\
\hline$[\mathrm{w}]$ & wary, where, west, wet, while, with, wine & 259 & 105 \\
{$[\mathrm{v}]$} & vary, vest, vet, vile, vine & 259 & 102 \\
{$[\mathrm{~s}]$} & seat, sick, sinking, sit, study, sin & 305 & 121 \\
{$\left[\int\right]$} & sheep, ship & 101 & 40 \\
{$[1]$} & lab, leaf, leap, lip & 206 & 83 \\
{$[\mathrm{t}]$} & feel, pal, peal, pill & 205 & 81 \\
\hline
\end{tabular}

\subsection{Data Annotation and Acoustic Measures}

The recordings of all participants were digitized at $16 \mathrm{kHz}$. All data were segmented and labelled automatically into individual phonetic segments using WebMaus, a webtool using forced-alignment algorithms (Kisler et al. 2017). They were then converted for further acoustic analysis into the EMU-SDMS format (Winkelmann et al. 2017, 2020), and all precalculated boundaries were checked manually and readjusted where needed. All analyses were carried out within $R$ (R Core Team 2020) with Winkelmann et al.'s (2020) $R$ package emuR.

We calculated formant frequencies and power spectra for the recordings used for this study. The frequencies of the first five formants (F1-F5) were calculated from the audio signal by means of Praat's (Boersma and Weenink 2020) built-in standard formant tracker using the Burg method (cf. Childers 1978, pp. 252-55). For female participants, the frequency range was set between 0 and $5500 \mathrm{~Hz}$, whereas for males, it was set between 0 and $5000 \mathrm{~Hz}$. In both cases, we used a frame shift of $6.25 \mathrm{~ms}$, a window length of $25 \mathrm{~ms}$, and pre-emphasis from $50 \mathrm{~Hz}$. Very few but obvious errors in the first two formants of the target sounds for which formants are relevant $([v, w]$ or $[1, t])$, such as when the first formant frequency (F1) was mistracked as a second formant frequency (F2), were manually corrected. A power spectrum was calculated for each of the sounds and later analyzed for [s, $]$, using a Discrete Fourier Transformation with a $40 \mathrm{~Hz}$ frequency resolution, a $5 \mathrm{~ms}$ Blackman window, and a $5 \mathrm{~ms}$ frame shift. Both formant frequencies $([\mathrm{v}, \mathrm{w}]$ or $[1, \mathrm{l}])$ and power spectra $\left[s, \int\right]$ were extracted at the temporal midpoints of the sounds. For the power spectra of $\left[\mathrm{s}, \int\right]$, we calculated the first spectral moment $\left(\mathrm{M}_{1}\right)$ in the frequency range 2500-6000 Hz using the moments function in the $R$ package emuR (Winkelmann et al. 2017).

The first spectral moment $\left(\mathrm{M}_{1}\right)$ represents the mean (sometimes called the centroid or center of gravity) of the spectral slice. We chose this measure for our [s-f] analysis, as it has been shown to be an effective acoustic parameter for distinguishing between these two sounds (Forrest et al. 1988), with $\mathrm{M}_{1}$ being the most effective of the spectral moments (Haley et al. 2010), and lower values indicating more [J]-like frication. As Kopečková et al. (2019) found that F2 is a useful measure for the distinction between English [v] and [w] (with low values for [w], and high values for [v]), we chose this as our [v-w] measure. For analysis of English "clear" and "dark" laterals [1, ł], we chose the distance between F1 and F2, as proposed by Lehiste (1962) and Carter (2002), with lower values showing increasingly "darker" laterals.

We did not apply any extrinsic speaker normalization technique, but instead, used Speaker as a random effects variable in the statistical analyses, whenever applicable. We decided against extrinsic speaker normalization, as we expected BIL speakers to possibly assimilate or dissimilate the phonological contrasts under study, and therefore, diminish or 
exaggerate the acoustic differences between the sound pairs. Even if sounds other than the ones in the sound pairs were involved in extrinsic speaker normalization, such a technique could potentially factor out these important differences. Note that the acoustic measure used for the lateral approximants [1, t], i.e., the distance between F1 and F2, already involves intrinsic speaker normalization.

\subsection{Statistical Analysis}

For each of the three sound pairs $\left(<\mathrm{w}>[\mathrm{v}-\mathrm{w}],<\operatorname{st}(\mathrm{r})>\left[\int \mathrm{t}_{\mathrm{s}-\mathrm{st}} \mathrm{x}\right],<\mathrm{l}>[1-\mathrm{t}]\right)$, we ran the same series of four linear mixed models (henceforth LMMs) in the R package lmerTest, version 3.1-3 (Kuznetsova et al. 2017), which makes use of the techniques in the package lme4, version 1.1-26 (Bates et al. 2015). Post hoc tests were carried out using the package emmeans (version 1.5.4; Lenth 2021). In both lmerTest and emmeans, we used Satterthwaite's method to calculate an approximation to the effective degrees of freedom in order to obtain $p$-values. In all these tests, we used the acoustic parameters (i.e., first spectral moment $\left(\mathrm{M}_{1}\right)$ for [s- $\left.\int\right], F 2$ for [v-w], and the distance between F1 and F2 for [1-t]) as dependent variables. The first LMM (LMM 1) tested whether the BIL speakers already show signs of L1 attrition in their monolingual utterances, by comparing the productions of MON speakers to BIL speakers in the non-CS speech. We took Phonological Category (two levels: the two members of a sound pair), Group (two levels: BIL vs. MON), and Gender (two levels: female vs. male) as fixed factors, and Speaker and Word as random factors.

The second LMM (LMM 2) compared the BIL speakers' productions of [w], [s] and [1] in CS utterances with the same sounds and the other member of the sound pair ([w], [S] and [1], respectively) in the non-CS utterances, to test whether code-switching had an effect on L2-induced changes, and if so, whether the changes were toward (assimilatory) or away from (dissimilatory) the respective counterpart. Fixed factors were Phonetic Category (3 levels: CS vs. non-CS [w], [s] or [ł] vs. non-CS ([w], [J] or [1]), Direction of L2-induced Influence (two levels: pro- vs. regressive, i.e., whether the tested sound occurs after or before the code-switch, respectively) and Gender (female vs. male); Speaker and Word were random factors. For the sound pair [1-t], we had to leave out the fixed factor Direction of L2 induced Influence, as there were no productions in the regressive context.

We then ran a third LMM (LMM 3) in order to quantify individual variation in the effect of code-switching. To this end, we ran LMM 2 (as above) but this time, with Speaker as a fixed factor. The BIL speakers who showed an effect of code-switching in LMM 3 were then, as a group, entered into a fourth LMM (LMM 4), in order to establish whether they showed any sign of L1 attrition in their non-CS speech that might have been obscured in the pooled analysis in LMM 1. To this end, their non-CS speech was compared to that of the MON speakers, in what is essentially a reanalysis of LMM 1, but this time, with a reduced pool of BIL speakers.

Finally, in order to determine the influence of the predictor variables $A o E, L o R, C+M$, $C-M$, amount of L1 use, amount of L2 use and L2 proficiency on L1 changes in the tested speech sound, we ran several multiple linear regression analyses with the BIL speaker group. We calculated speaker-specific estimates taken from LMM 3's Estimated Marginal Means results as a quantification of shift sizes of CS [w, s, t] away from non-CS [w, s, t], and used these measures as dependent variables in the multiple linear regression tests.

\section{Results}

\section{1. [v] vs. [w]}

\subsubsection{Monolingual vs. Bilingual [v] and [w] in Non-CS Contexts}

LMM 1 (see Section 2.4) with F2 as the dependent variable, Phonological Category (2 levels: [v] vs. [w]), Group (two levels: BIL vs. MON), and Gender as fixed factors, and Speaker and Word as random factors revealed significant main effects for Phonological Category $(\mathrm{F}[1,14.9]=318.4, p<0.001)$, Group $(\mathrm{F}[1,31.1]=6.6, p<0.05)$, and Gender $(\mathrm{F}[1,31.1]=21.9, p<0.001)$ (see Figure 1). We also found significant interactions between Phonological Category and Group $(\mathrm{F}[1,30.8]=6.7, p<0.05)$. None of the other two- and 
three-way interactions were significant. Post hoc pairwise comparisons with Estimated Marginal Means revealed significant F2 differences between [v] and [w] in all pairwise comparisons ( $p<0.001$ for each Gender and Group combination). There was, however, no significant difference between the [w]s produced by the BIL and MON group. Similarly, for the [v]s produced by the males, no significant differences between the BIL and MON were found. However, for the females, F2 in [v]s was found to be significantly higher in BIL as compared to MON $(p<0.05)$.

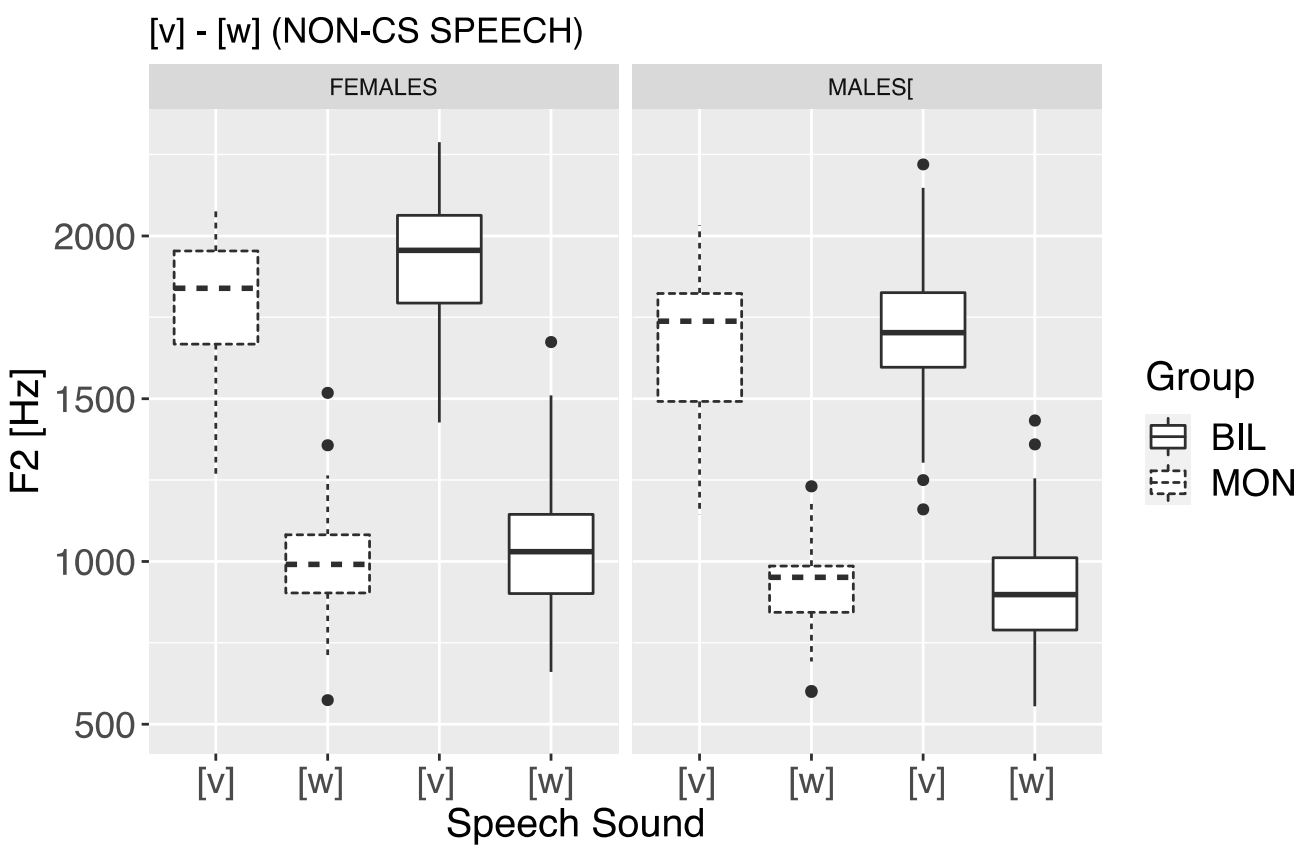

Figure 1. The F2 of intended [v] and [w] sounds in English words, spoken by MON (dashed) and BIL speakers (solid) in non-CS environments. The left panel shows data for females, the right panel for males.

\subsubsection{Comparison of Bilinguals' Productions in Non-CS vs. CS Contexts}

LMM 2 (see Section 2.4) conducted with F2 as the dependent variable, Phonetic Category (3 levels: non-CS [v] vs. non-CS [w] vs. CS [w]), Direction of L2-induced Influence and Gender as fixed factors, and Speaker and Word as random factors revealed significant main effects for Phonetic Category $(\mathrm{F}[2,16.6]=194.2, p<0.001)$ and $\operatorname{Gender}(\mathrm{F}[1,23.0]=12.4, p<0.01)$, but not for Direction of L2-induced Influence (as shown in Figure 2). There also were no significant interactions. Estimated Marginal Means showed that non-CS [v] in both males and females is significantly different from non-CS [w], but also CS [w] $(p<0.001$ in all cases), showing no evidence of a categorical shift. The shift of CS [w] away from non-CS $[w]$ reaches significance only in males under the regressive influence of German $(p<0.05)$, but not under progressive influence. However, for both females and males, the differences between progressive and regressive German influences on English [w] in CS speech are not significant. Visual inspection of Figure 2 shows that some of the outliers for CS [w] are clearly in the area of the [v] category. This will be discussed further in Section 3.1.3.

\subsubsection{Individual Variation}

LMM 3 (see Section 2.4) reveals that five speakers (four males and one female) show significant shifts of CS [w] away from non-CS [w], as shown in Figure 3. In the female speaker (BIL021), these shifts are significant for both the progressive $(p<0.05)$ and the regressive $(p<0.001)$ case. In the four males (BIL002, BIL005, BIL008, and BIL018), however, the shift only reaches significance under regressive L2-induced influence $(p<0.001$ for each), but not under progressive influence (although there is a tendency for the progressive 
case in speaker BIL008, with $p<0.1$ ). As can be seen in Figure 3, while some individual shifts of [w] are small acoustic shifts, other shifts are more categorical and overlap with [v].

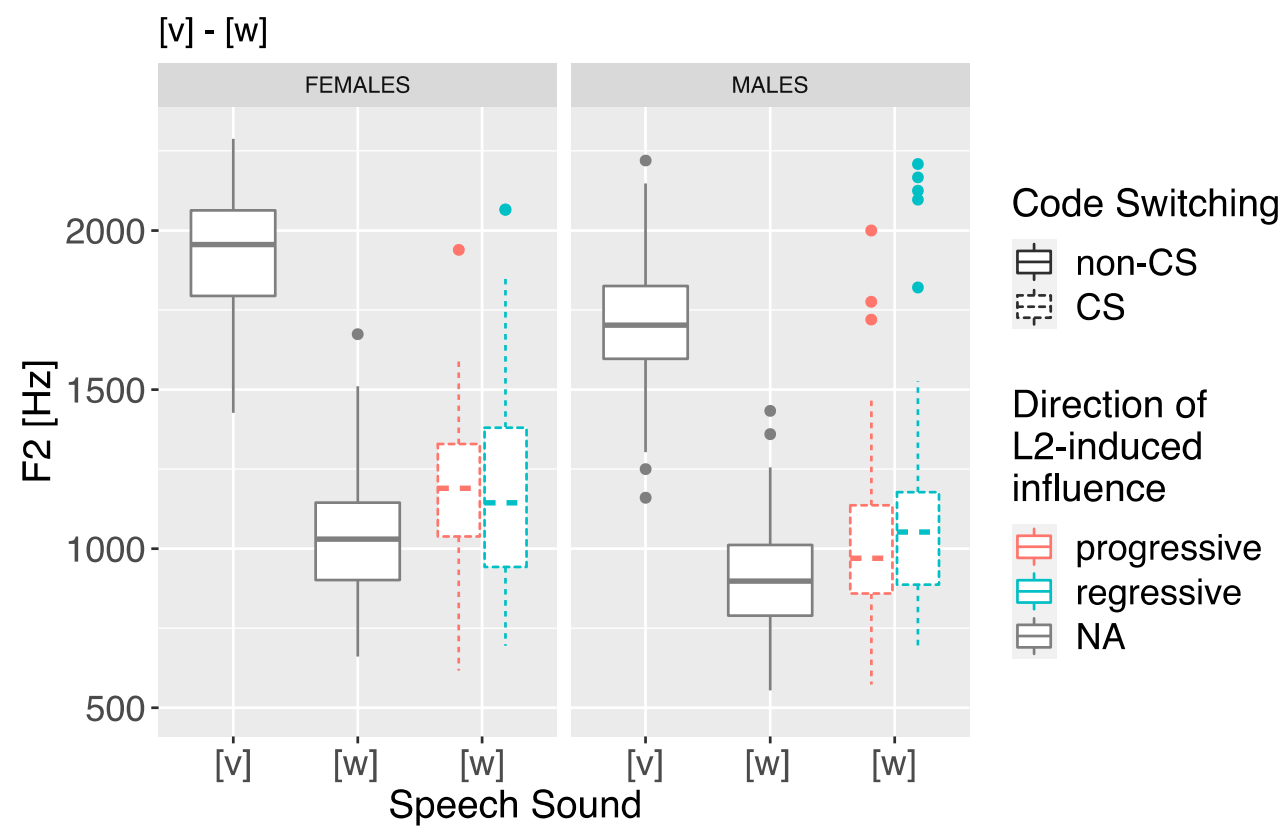

Figure 2. F2 of the intended [v] and $[\mathrm{w}]$ sounds in English words, spoken by BIL speakers in non-CS (solid) and in CS environments; productions in CS environments are divided into progressive (red) and regressive (blue) L2-induced influences. The left panel shows female data, the right panel male data.

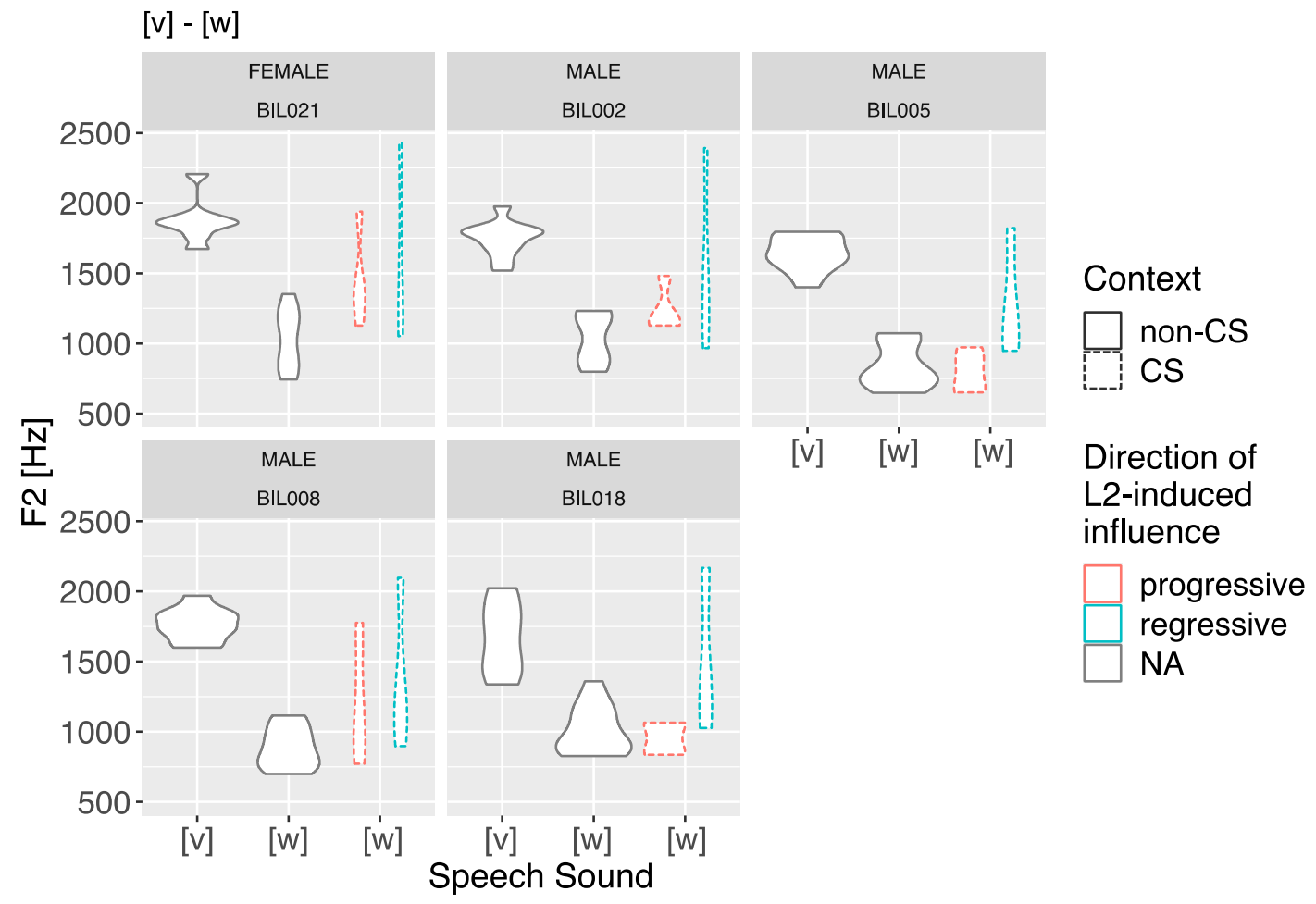

Figure 3. F2 of intended [v] and [w] sounds in English words, spoken by 5 (one female, four male) BIL speakers in non-CS (black), and of [w] in CS (colored) environments, with the latter being divided into contexts with possible progressive (red) and regressive (green) L2-induced influences. Only speakers with significant differences are presented. For the sake of a better presentation of potentially multimodal (and therefore non-normal) distributions of the data, we opted for violin plots instead of boxplots, because a violin plot shows the full distribution of the data as rotated kernel density plots on both sides. 
An analysis (LMM 4) of the non-CS [w] and [v] productions of only these five speakers as compared to the MON group with fixed factors Group and Gender and random factors Speaker and Word revealed a significant main effect for Gender ( $\mathrm{F}[1,11.0]=9.6, p<0.05)$ only (reflecting the sex-related differences in vocal tract sizes and, therefore, formants), but no main effect for group. As an analysis of the Estimated Marginal Means confirmed, there were no significant differences between MON speakers' [v] and BIL speakers' [v] in both males and females; more importantly, the same is true for both speaker groups' $[\mathrm{w}]$ sounds (see Figure 4 for descriptive details).

\section{[v] - [w] (NON-CS SPEECH)}

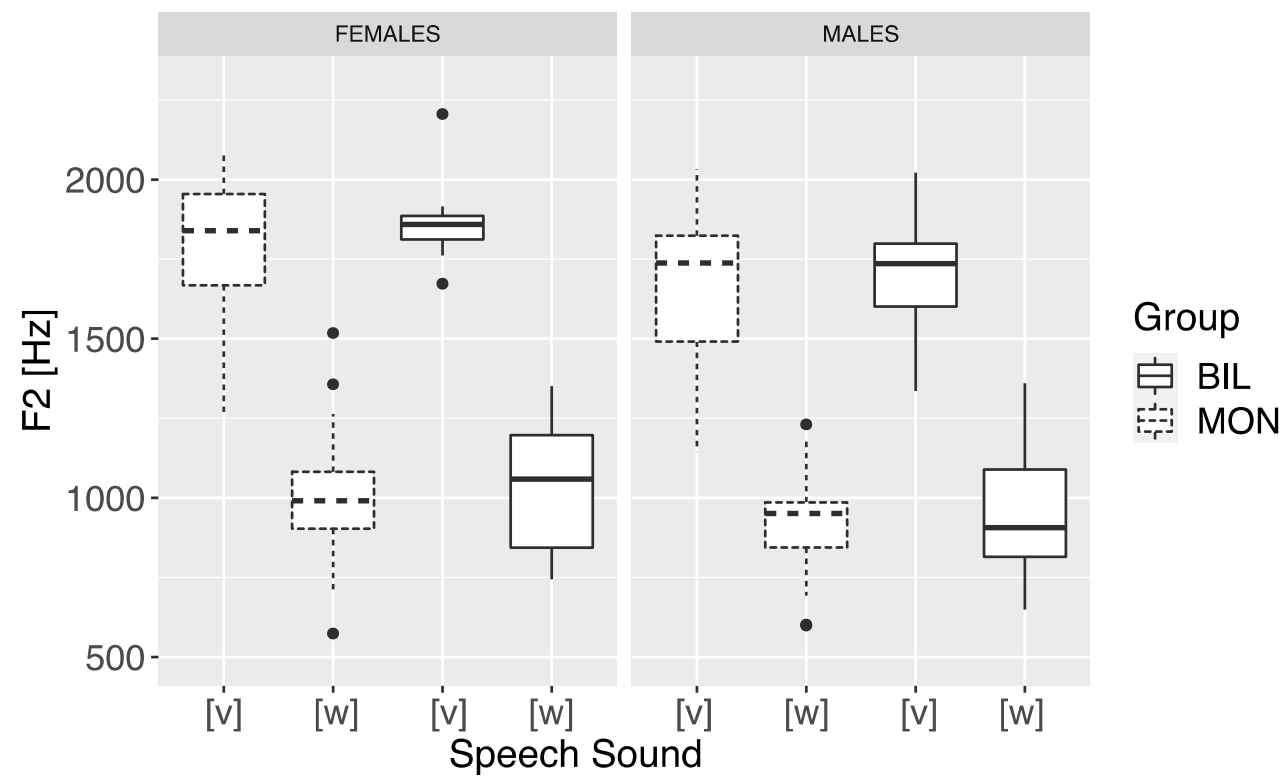

Figure 4. F2 of intended [v] and [w] sounds in English words, spoken by the same MON speakers (dashed) that already appeared in Figure 1, and by the five BIL speakers (solid) in non-CS environments, who were shown to have shifted CS [w] away from non-CS [w]. The left panel shows female data, the right panel male data.

\subsubsection{Influence of Predictor Variables}

As described under Section 2.4, shift sizes of CS [w] away from non-CS [w] were obtained by taking the speaker-specific estimates of the Estimated Marginal Means analysis of LMM 3. The value 0 denotes the position of non-CS [w]; negative numbers denote a shift of CS [w] towards non-CS [v]. Only one of the predictor variables $A o E, L o R, C+M, C-M$, amount of L1 use, amount of $L 2$ use and $L 2$ proficiency turned out to be significantly correlated with shift size: amount of $L 2$ use (Adjusted $\mathrm{R}^{2}=0.13, p<0.05$ ). As Figure 5 demonstrates, shift size of CS [w] increases with increasing amount of L2 use.

\section{2. [s] vs. [ $]$}

\subsubsection{Monolingual vs. Bilingual [s] and [J] in Non-CS Contexts}

LMM 1 (see Section 2.4) with the first spectral moment (M1) as the dependent variable, Phonological Category (2 levels: [s] vs. [J]), Group, and Gender as fixed factors, and Speaker and Word as random factors revealed significant main effects for Phonological Category $(\mathrm{F}[1,31.1]=300.0, p<0.001)$ and Group $(\mathrm{F}[1,30.9]=12.0, p<0.01)$, but no effect for Gender (see Figure 6). Additionally, there was a significant interaction between Phonological Category and Gender $(\mathrm{F}[1,31.1]=10.9, p<0.01)$. Pairwise comparisons by means of the Estimated Marginal Means showed significant differences between [J] and [s] in all possible comparisons $(p<0.001$ each). In both male and female speakers, there were no significant differences in either [s] or in [ [] between MON and BIL. 


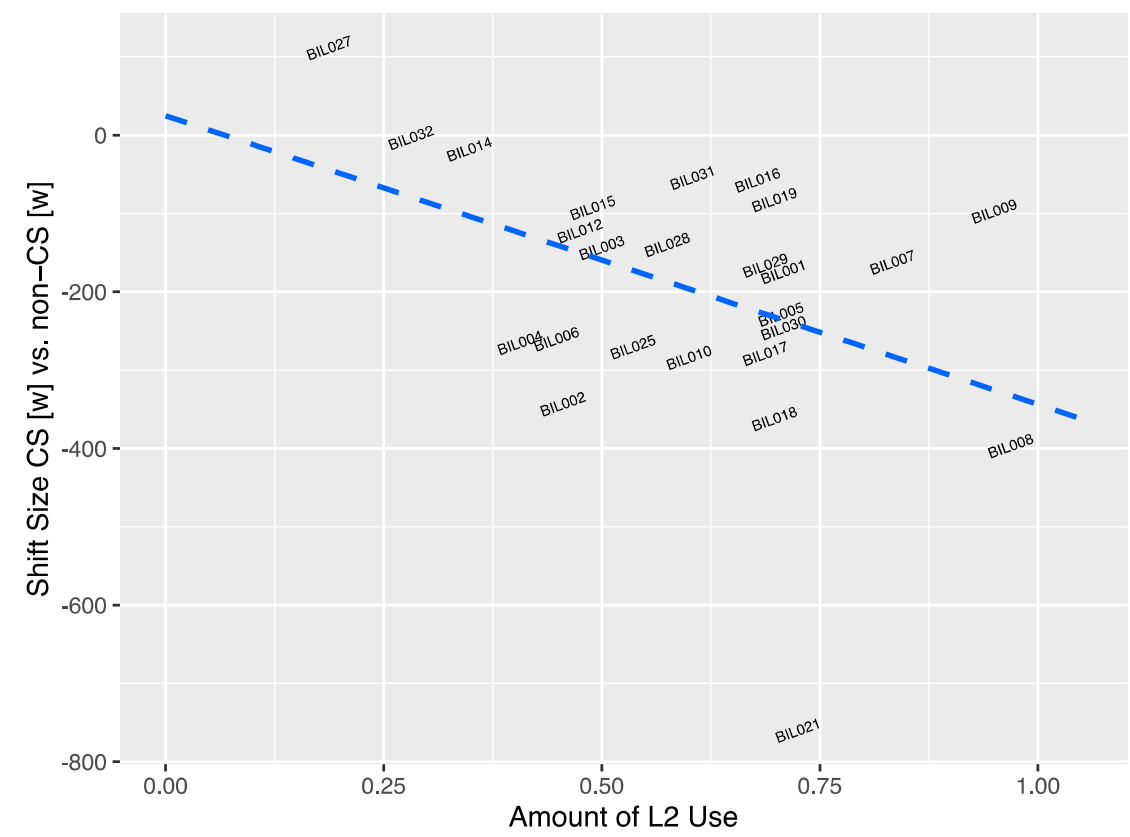

Figure 5. The shift size of CS [w] vs. non-CS [w] as a function of the predictor variable amount of L2 use. Regression line superimposed.

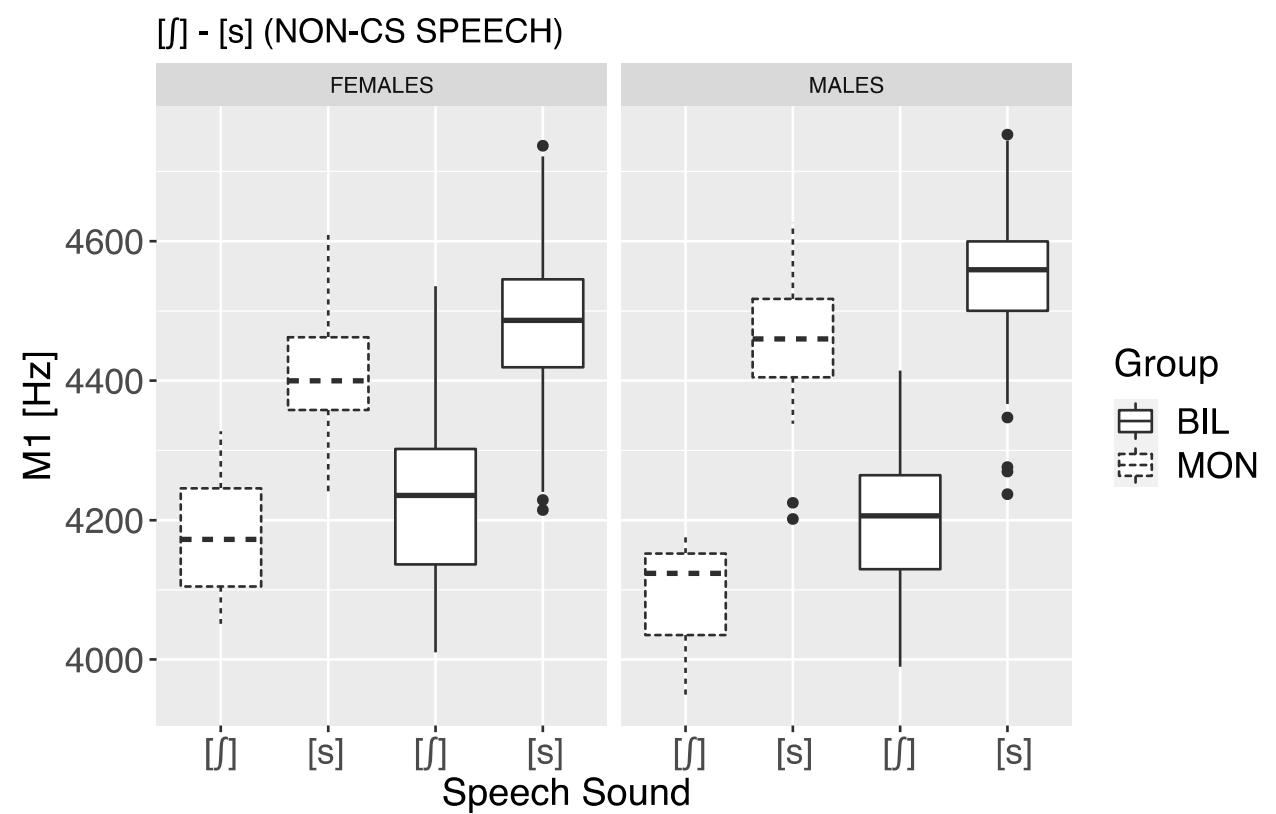

Figure 6. The first spectral moment of intended [j] and [s] sounds in English words, spoken by MON speakers (dashed) and BIL speakers (solid) in non-CS speech. The left panel shows female data, the right panel male data.

\subsubsection{Comparison of Bilinguals' Productions in Non-CS vs. CS Contexts}

LMM 2 (see Section 2.4) with M1 as the dependent variable, Phonetic Category (3 levels: non-CS [J] vs. non-CS [s] ${ }^{4}$ vs. CS [s]), Direction of L2-induced Influence and Gender as fixed factors, and Speaker and Word as random factors revealed one significant main effect only, namely for Phonetic Category (F[2, 21.4] = 58.3, $p<0.001)$, but none for Direction of L2-induced Influence or Gender. However, there was a significant interaction between Phonetic Category and Gender $(F[2,23.2]=9.6, p<0.001)$. A post hoc analysis with Estimated Marginal Means showed no effects between the CS [s] in progressive vs. regressive environments. As Figure 7 suggests, there are no significant differences between non-CS [s] and CS [s] sounds 
in females (under both directions of L2-induced influence). In males, however, CS [s] is significantly shifted away from their non-CS [s] counterparts with $p<0.001$ in both cases under both regressive and progressive L2-induced influence. However, the CS [s] does not overlap with non-CS [J] (suggesting a subtle acoustic rather than a categorical shift), showing no evidence of a categorical shift, neither in females nor in males, and irrespective of the direction of the L2 influence.

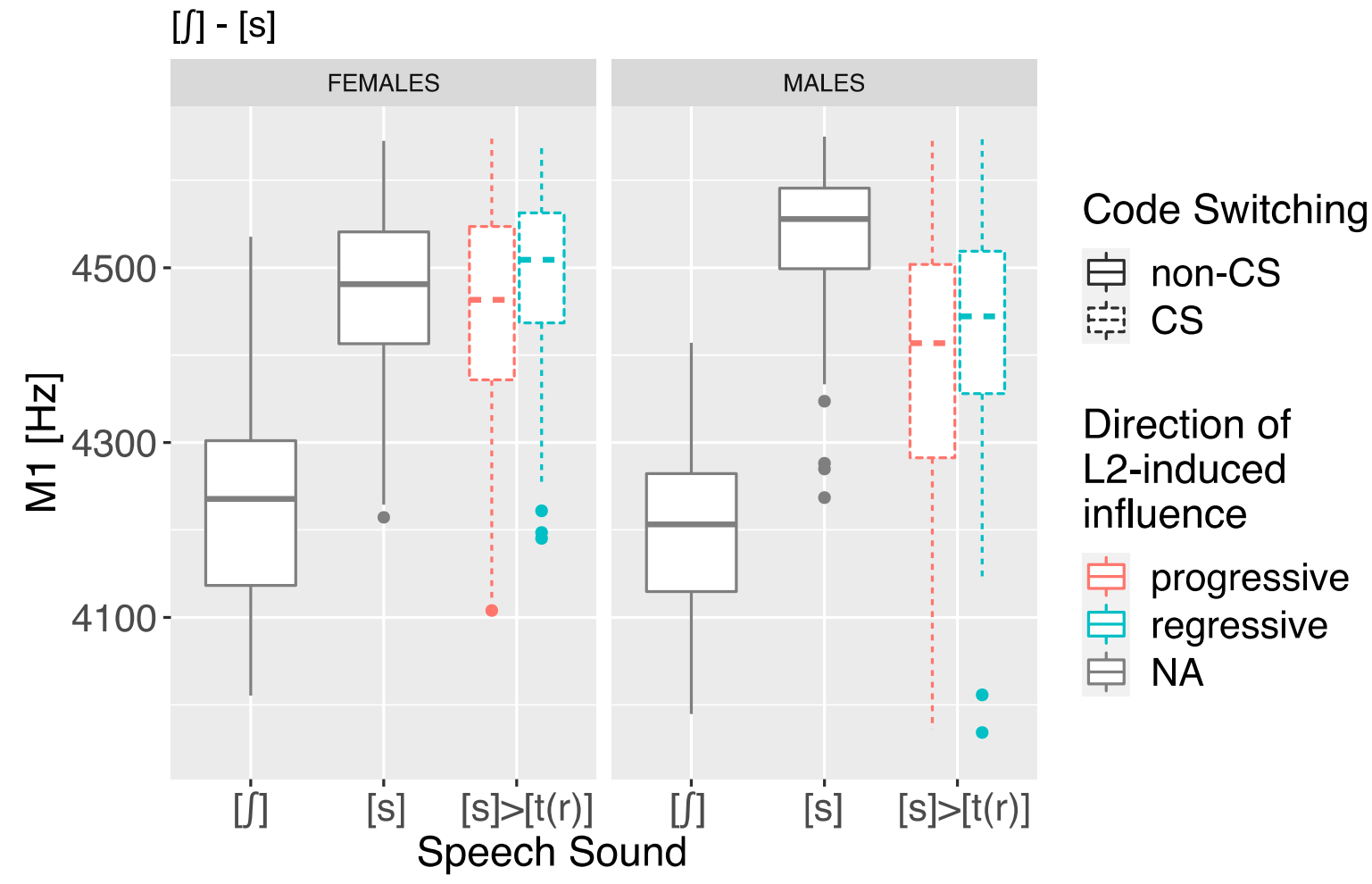

Figure 7. The first spectral moment of intended [J] and [s] sounds in English words, spoken by BIL speakers in non-CS (solid) and CS (dashed) speech; productions in CS environments are divided into progressive (red) and regressive (blue) L2-induced influences. The left panel shows female data, the right panel male data.

\subsubsection{Individual Variation}

Individual variation was examined by means of LMM 3 (see Section 2.4), which revealed that 2 out of $11(=18.2 \%)$ females showed significant shifts of [s] in CS mode away from their counterparts in non-CS mode. However, out of 14 men, 11 (=78.6\%) showed significant shifts in CS [s]. Only these women and men are shown in Figure 8. Of those, six speakers (BIL006, BIL010, BIL014, BIL028, BIL029 and BIL030) only shift CS [s] in progressive, but not regressive, contexts; two speakers (BIL008, BIL019) shift only under regressive, but not progressive, influence away from non-CS [s], towards more [S]-like values. All other speakers (BIL003, BIL005, BIL016, BIL018, BIL032) shift CS [s] significantly away from non-CS [s] under both regressive and progressive German influence; for these, no significant difference was found between the two conditions.

LMM 4 (see Section 2.4), which compared the non-CS [s] and [ $]$ ] productions of only these 13 speakers as compared to the MON group with fixed factors Group and Gender and random factors Speaker and Word, revealed a significant main effect for Group $(\mathrm{F}[1,19.0]=9.6, p<0.01)$, but not for Gender, as shown in Figure 9. There are no significant interactions, with the exception of the three-way interaction of Phonological Category, Group, and Gender $(\mathrm{F}[1,18.9]=5.2, p<0.05)$. The Estimated Marginal Means analysis showed no statistically significant differences in either males or females between the [ $]$ ] sounds of MON and the BIL speakers. The BIL speakers do, however, differ significantly from the MON speakers for [s] (in both females and males: $p<0.01$ ), with the [s] in the BIL shifted away from [s] in MON speakers. Interestingly though, this shift was not towards more 
[ $]$-like values, but rather, in the opposite direction, "overshooting" the [s] values of the MON group.

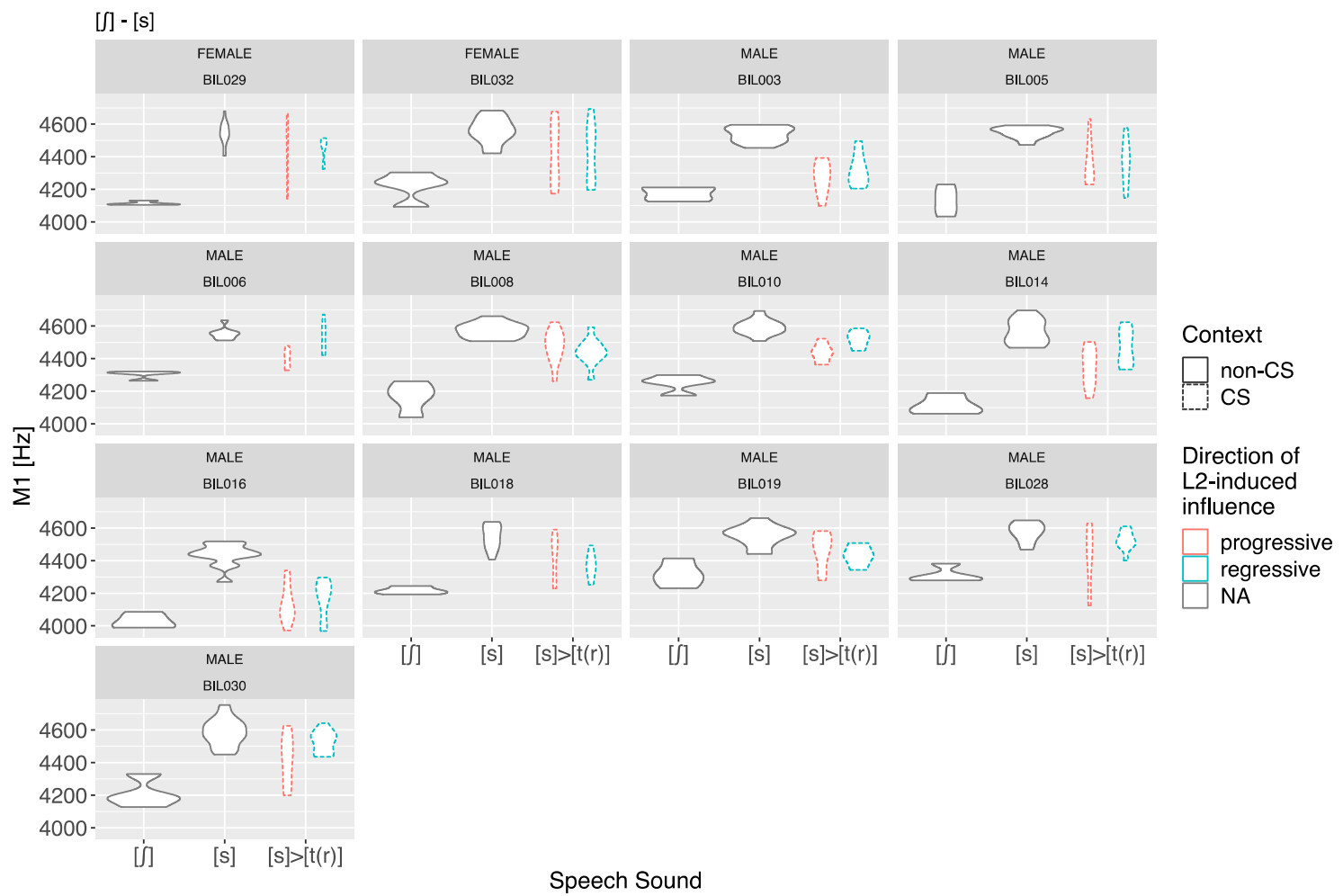

Figure 8. The first spectral moment of intended [J] and [s] sounds in English words, spoken by 13 (2 female, 11 male) of the 25 BIL speakers, in non-CS (black), and of [s] in CS (colored) environments, with the latter being divided into contexts with possible progressive (red) and regressive (green) L2-induced influences.

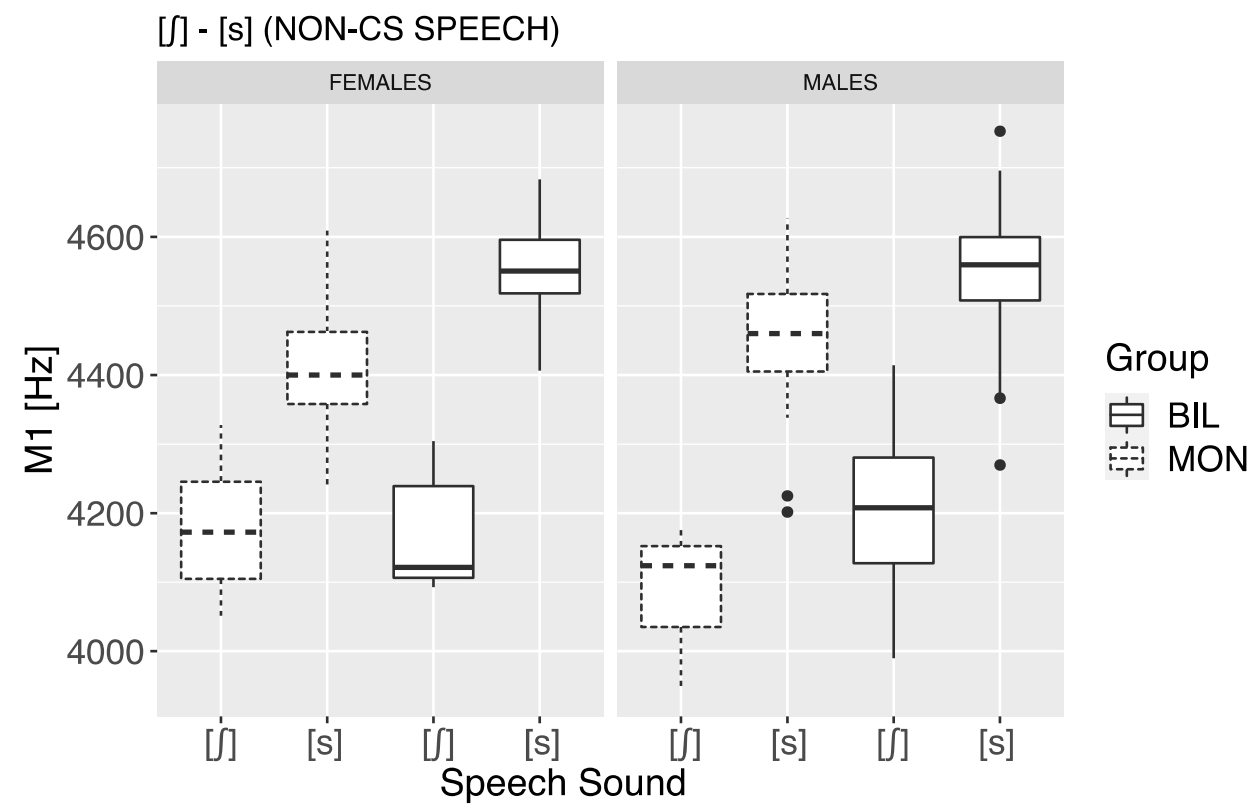

Figure 9. The first spectral moment of intended [J] and [s] sounds in English words in non-CS environments, spoken by the MON speakers (dashed), and by a selection of BIL speakers (solid), who have been shown to have shifted CS [s] away from non-CS [s]. The left panel shows female data, the right panel male data. 


\subsubsection{Influence of Predictor Variables}

None of the predictor variables $A o E, L o R, C+M, C-M$, amount of $L 1$ use, amount of $L 2$ use and $L 2$ proficiency turned out to be significantly correlated with shift sizes of CS [s].

\section{3. [l] vs. [t]}

As our group analyses for the other two sound pairs showed no effect of the position of the observed L2-induced changes (before or after the German item), we decided to include the sounds [l] and [ 1$]$, for which we only had sentences for the progressive environment.

\subsubsection{Monolingual vs. Bilingual [1] vs. [1] in Non-CS Contexts}

LMM 1 (see Section 2.4) with the distance between F1 and F2 as the dependent variable in a linear mixed model with Phonological Category (with 2 levels, [1] vs. [1]), Group and Gender as fixed factors and Speaker and Word as random factors revealed a significant main effect each for Phonological Category $(\mathrm{F}[1,9.2]=106.7, p<0.001)$ and for Gender $(\mathrm{F}[1,30.9]=8.3, p<0.01)$, but none for Group, as shown in Figure 10. There also was a significant interaction between the factors Phonological Category and Gender $(\mathrm{F}[1,30.9]=4.5$, $p<0.05)$. For both males and females, an Estimated Marginal Means analysis showed that [1] and [ 1$]$ were well separated in all cases $(p<0.001$ in all pairwise comparisons), and that there were no differences between MON and non-CS [1] or between MON and non-CS [1] (cf. Figure 10).

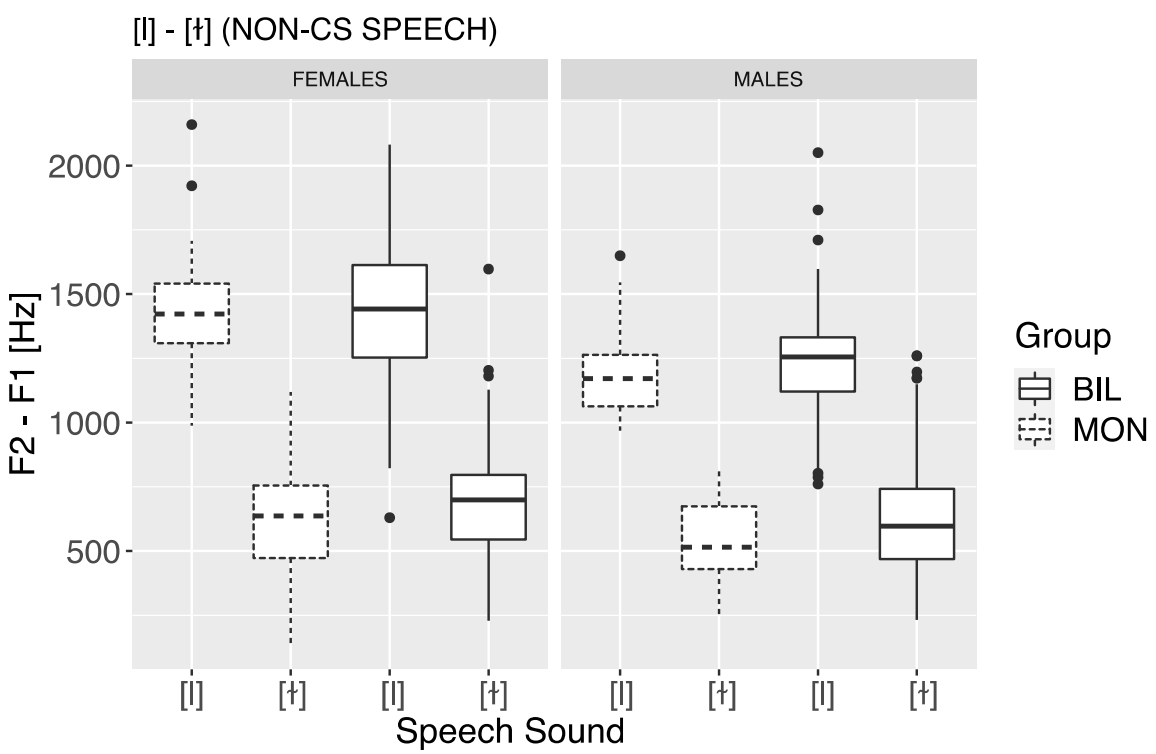

Figure 10. The distance between F1 and F2 of intended light [1] and dark [ $\mathrm{t}]$ sounds in English words, spoken by MON speakers (dashed) and BIL (solid) in non-CS speech. The left panel shows female data, the right panel male data.

\subsubsection{Comparison of Bilinguals' Productions in Non-CS vs. CS Contexts}

LMM 2 (see Section 2.4) with the distance between F1 and F2 as the dependent variable, Phonetic Category (3 levels: non-CS [1] vs. non-CS [1] vs. CS [ 1$]$ ) and Gender as fixed factors, and Speaker and Word as random factors showed no significant interaction between Phonetic Category and Gender, but main effects for both factors individually (Phonetic Category: $F[2,10.8]=41.0, p<0.001$, Gender: $F[1,22.9]=5.0, p<0.05)$, as shown in Figure 11. An analysis of the Estimated Marginal Means confirmed this: non-CS [1] was always significantly different from both non-CS and CS [ 1 ], in both men and women (always $p<0.001$ ), but neither showed significant differences between non-CS vs. CS [ł]s. 


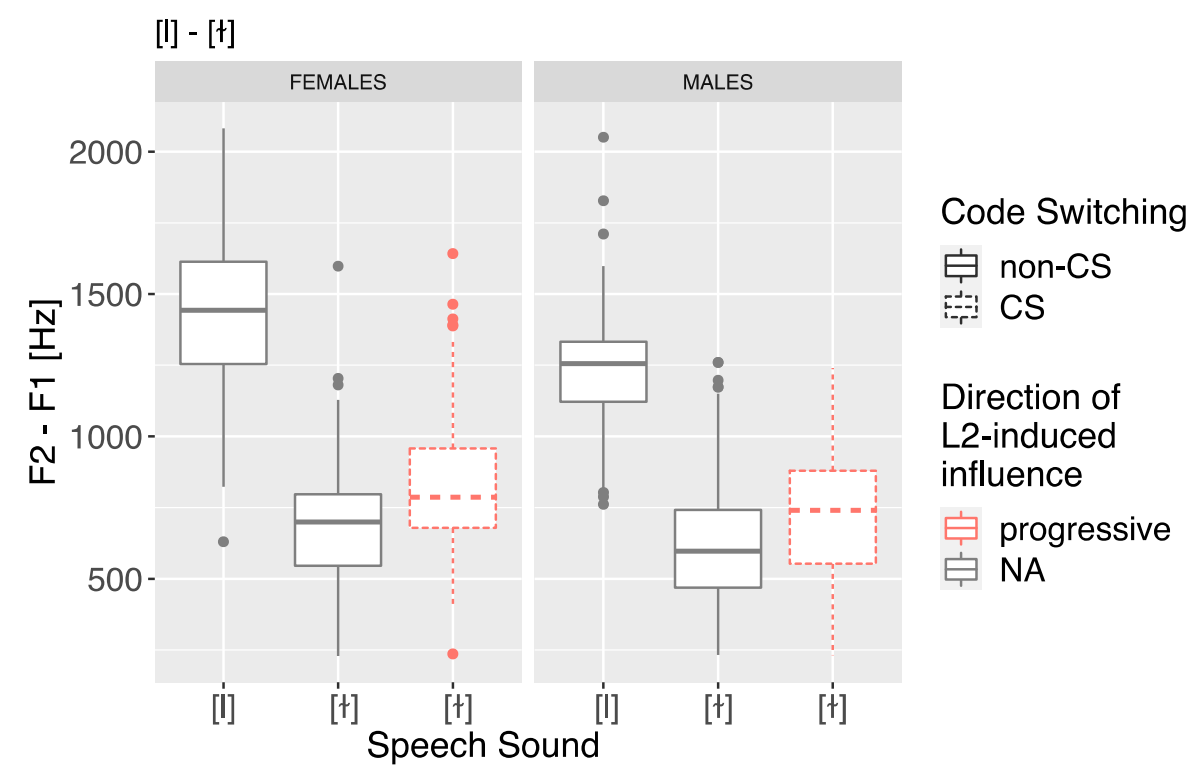

Figure 11. The distance between F1 and F2 of intended [1] and [ 1$]$ sounds in English words, spoken by BIL speakers in non-CS (solid) and CS (dashed) speech; productions in CS environments were only available in progressive (red) L2-induced influence. The left panel shows female data, the right panel male data.

\subsubsection{Individual Variation}

LMM 3 (see Section 2.4) showed that only 3 out of 25 BIL speakers showed significant shifts of CS [ $\mathrm{t}$ ] away from non-CS / $\mathrm{t} /: 2$ females (BIL015: $p<0.01$; BIL029: $p<0.05$ ) and 1 male (BIL025: $p<0.05)$. Figure 12 presents descriptive details of these three speakers.

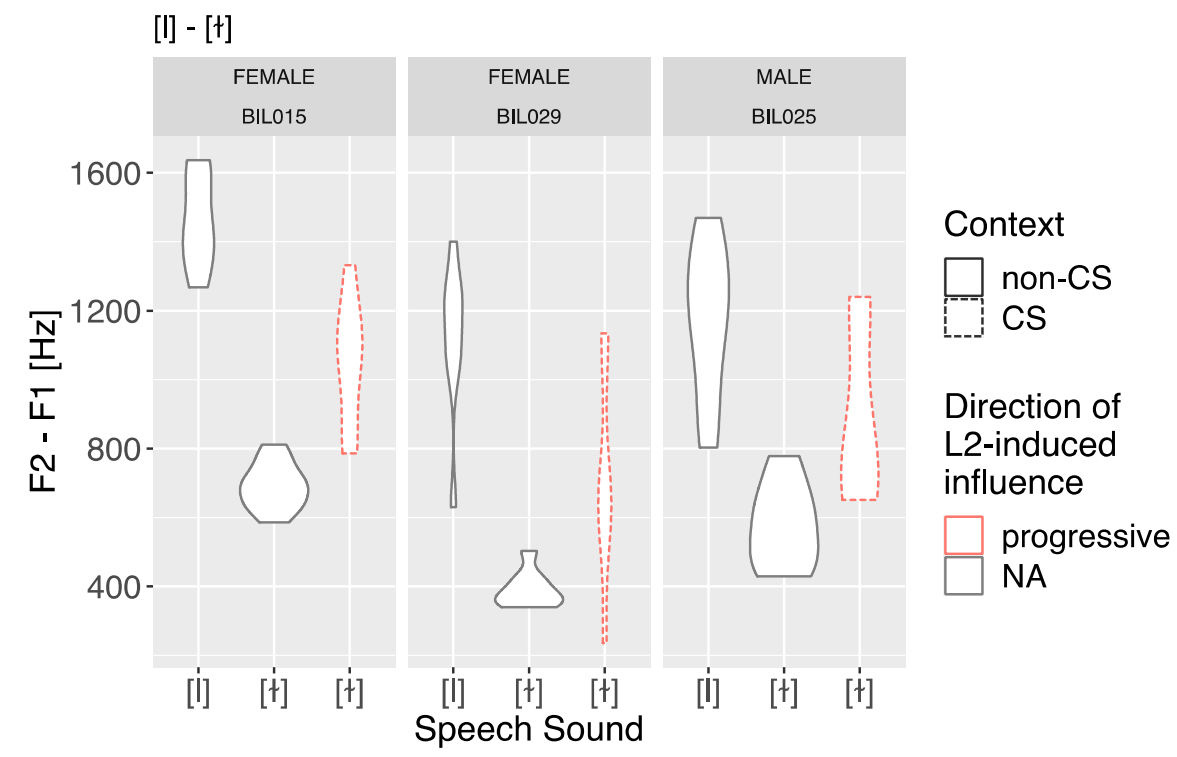

Figure 12. The distance between F1 and F2 of intended [1] and [ 1$]$ sounds in English words, spoken by 3 ( 2 female, 1 male) of the 25 BIL speakers, in non-CS (black), and of [ 1 ] in CS (colored) environments (only progressive (red) L2-induced influences were available).

As before, we conducted the same analysis as in Section 3.3.1 with these three speakers. The LMM revealed no significant main effects, neither for Group nor for Gender, and also no significant interactions. This was further confirmed by an Estimated Marginal Means analysis, which showed no significant differences, either between MON [1] and non-CS [1], or between MON-[ł] and non-CS [ł] (cf. Figure 13), across both males and females. 


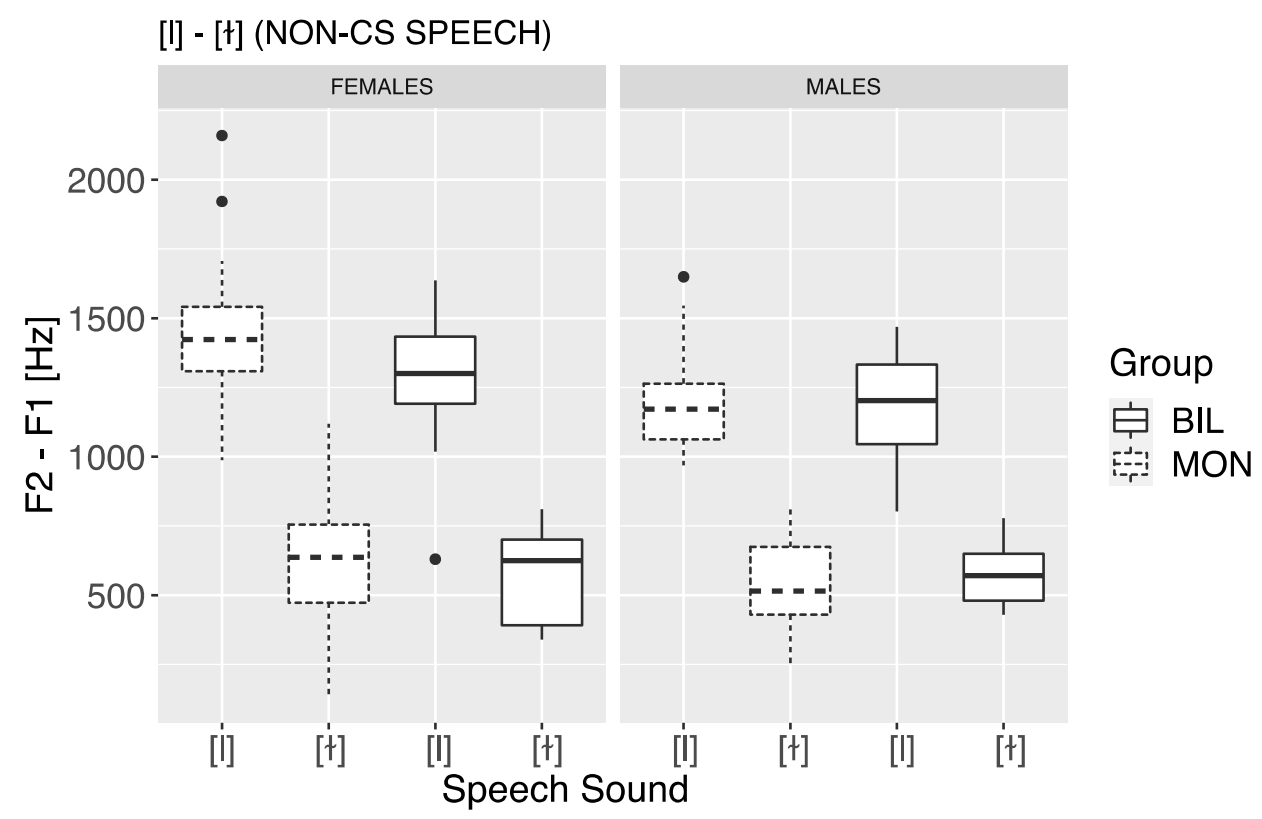

Figure 13. The distance between F1 and F2 of intended [1] and [ $\mathrm{t}$ ] sounds in English words, spoken by the MON speakers (dashed), and by a selection of BIL speakers (solid) in non-CS environments who have been found to have shifted CS [ $\mathrm{t}$ ] away from non-CS [ $\mathrm{t}]$. The left panel shows female data, the right panel male data.

\subsubsection{Influence of Predictor Variables}

None of the predictor variables $A o E, L o R, C+M, C-M$, amount of L1 use, amount of L2 use and L2 proficiency were significantly correlated with the shift sizes of CS [1] in our regression analyses.

\section{Discussion}

This paper set out to test the effect of dual language activation on the occurrence of L2-induced changes in the L1 speech of late English-Austrian sequential bilinguals who emigrated to Austria in adulthood. The purpose of the study was threefold. First, it sought to determine whether sounds produced in a code-switched context where both languages are thought to maximally interact (e.g., Green 1998; Olson 2013; Van Hell and Dijkstra 2002) are more prone to L2-induced changes in L1 speech than sounds that are produced in a monolingual (non-code-switched) context. Secondly, where an effect of code-switching was found, we aimed to examine whether it equally affected all the sounds under investigation, and whether the direction of L2-induced influence mattered, i.e., whether influences are more apparent in segments that occur before (regressive influence) or after a switch (progressive influence). Finally, the study sought to determine whether the predictor variables $A o E, L o R, C+M, C-M$, amount of L1 use, amount of $L 2$ use and $L 2$ proficiency could explain any of the observed changes in L1 speech production. In what follows, we will discuss the findings and implications for each of these issues in turn.

\subsection{The Effect of Dual Language Activation on L2-Induced Changes in L1 Speech}

As the BIL participants in our study all immigrated to Austria in adulthood, their L1 speech might have undergone some form of attrition, given that attrition is found to be widespread (de Leeuw 2019b; Mayr et al. 2020) and a considerable number of our participants had lived in Austria for many years. Some changes to their L1 speech may, therefore, have already been present in their productions of monolingual (English) noncode-switched utterances. We therefore first compared the BIL speakers' production of the three sound pairs under investigation in the monolingual English utterances with the same pairs produced by the MON speakers. Results revealed no significant differences 
between the BIL and MON speakers in any of the three sounds that were expected to trigger L2-induced influences (i.e., [w], [s] and [t]). Results also showed that the BIL speakers were able to keep the two members of each sound pair well separated. We then compared the sounds [w], [s] and [ $\mathrm{t}]$ produced by the BIL speakers in the bilingual (code-switched) utterances with the same sounds and the other member of the sound pair ([v], [J] and [1]), respectively, in order to establish whether sounds produced in a code-switched context are more susceptible to L2-induced changes than those produced in a monolingual (noncode-switched) context, and if so, whether the changes are toward (assimilatory) or away from (dissimilatory) its counterpart. The results showed that the code-switched tokens did differ from the tokens produced in a monolingual context, with [w] and [s] shifted toward (assimilated to) the other member of the sound pair ([v] and [J], respectively), although no difference between the participants' productions was observed across contexts for [ $[$ ]. This shows that code-switching and its resulting dual language activation leads to an increase in L2-induced changes in L1 speech. ${ }^{5}$ Interestingly, although we expected to find more L1 speech changes in the bilingual than in the monolingual context, there were, in fact, no changes at all in the monolingual context in any of the three sounds that were expected to trigger L2-induced transfer. This suggests that the observed L1 speech changes are transient in nature and are reversed when the linguistic environment changes (in this case, from a code-switched to a monolingual context). ${ }^{6}$ We therefore prefer not to refer to the observed changes in code-switched speech as L1 attrition but rather as temporary drifts akin to the gestural or phonetic drifts reported in inexperienced L2 learners who are, for a limited time, intensively exposed to the L2, or experience regular changes in their linguistic environment (Chang 2012, 2013; Dmitrieva et al. 2020; Kartushina et al. 2016; Sancier and Fowler 1997; Tobin et al. 2017). These drifts are also reported to be temporary in nature and are fully (Kartushina and Martin 2019) or partially (Chang 2019) reversible. Regularly travelling between their L1- and L2-speaking countries or short-term exposure to the L2 in inexperienced L2 learners who still rely heavily on their L1 will lead to "ad hoc dual language activation" (Mayr et al. 2020, p. 14) where both languages are highly active for a limited period of time, similarly to what happens during code-switching. While dual language activation has led to temporary drifts in L1 speech in a code-switched context, it is certainly possible that they may be a precursor to more persistent changes that may become apparent over time (see also Mayr et al. 2020). After all, the features affected in studies on phonetic drift, such as VOT (e.g., Chang 2012, 2013) and vowel formants (e.g., Kartushina and Martin 2019), are often also the ones that are reported to be affected in studies on long-term phonetic changes to L1 speech (e.g., Bergmann et al. 2016; Kornder and Mennen 2021; Mayr et al. 2012; Stoehr et al. 2017). If this is the case, it may have important implications for research on L1 speech attrition, as studies on code-switched speech may highlight those features that, over time, may lead to more persistent changes in L1 speech, and may thus be able to predict which features are vulnerable to L1 attrition and which may be resistant to change.

\subsection{Scale and Direction of L2-Induced Influences}

This leads us to the question of whether dual language activation by means of codeswitching affected some segments more than others. Our results showed that of the three sounds that were expected to show an influence of the L2, only [w] and [s] were found to have shifted toward the other member of the pair (i.e., in the direction of the inserted German sound) in code-switched utterances, whereas no shift was found for [ 1$]$. Just as not all sounds are equally affected by L1 attrition (Bergmann et al. 2016; Mayr et al. 2012; Stoehr et al. 2017), code-switching also does not lead to L2-induced changes in all sounds, with some more affected by code-switching than others. This was also reflected in the individual analyses. None of the individuals who showed an effect of code-switching exhibited shifts in all three sounds, and roughly a quarter (24\%) displayed shifts in two of the sounds under investigation (in all cases, [w] and [s]). Most shifts occurred in [s] (52\% of participants), followed by $[\mathrm{w}](20 \%)$ and [ 1$](8 \%)$. This suggests that although all three 
sounds may be vulnerable to change, out of the three sounds under investigation, [s] is the most likely to undergo L2-induced changes in a code-switching environment. It should be noted that the tokens for [s] in the code-switched utterances were always adjacent to either $/ \mathrm{t} /$ or $/ \mathrm{t} \mathrm{I} /$, whereas due to our restricted set of control materials, [s] in the noncode-switched utterances was only adjacent to $/ \mathrm{t} /$ in one word ( $<$ study $>$ ) and occurred in prevocalic position in the other five words ( $<$ seat $>,<$ sick $>,<\operatorname{sinking}>,<$ sit $>$, and $<\sin >$ ). We therefore cannot entirely exclude the possibility that the reported lowering of the first spectral moment in the code-switched utterances might-in part-be influenced by this imbalance in materials across conditions, particularly given that coarticulatory effects of this kind have been reported (albeit for Australian English varieties) for [s] followed by stop-vowel sequences and stop-rhotic-vowel sequences (Stevens and Harrington 2016). However, as mentioned before (footnote 3), no significant differences were found in MON or BIL speakers between the [s] tokens before / $t /$ and the prevocalic [s] tokens produced in monolingual utterances, nor in the code-switched tokens with [s] before $/ \mathrm{t} /$ and [s] before / t. I . Additionally, while in Stevens and Harrington (2016) study, [s] may have retracted in certain contexts, it was never found to overlap with [ $\left.\int\right]$. However, some of the BIL speakers in our study showed an overlap of [s] in their code-switched utterances with [S] in their monolingual utterances (cf. Section 3.2.3). This, and the fact that the other sound pairs $(<\mathrm{w}>/ \mathrm{v}-\mathrm{w} /$ and $<\mathrm{l}>/ \mathrm{l}-\mathrm{t} /)$ showed similar patterns of shifts away from one sound towards the other end of the sound pair, makes us confident that we are not reporting mere artifacts.

So how can the differences in observed changes across the three sound pairs be explained? A possible explanation comes from Markedness Theory, according to which sounds that are infrequent in the world's languages, i.e., typologically marked sounds, pose greater articulatory and perceptual difficulties than more frequent, unmarked sounds (Eckman 1977, 1991). Indeed, marked sounds have been shown to be acquired later by children (e.g., Dinnsen et al. 1990; Watts and Rose 2020) and second language learners (Carlisle 1997, 1998). It therefore stands to reason that marked sounds may also be more vulnerable to shifts in code-switched settings than unmarked ones. However, according to the UPSID corpus of 451 languages (Maddieson 1984; Maddieson and Precoda 1990), [t] is much more marked (occurrence: 1.11\% of languages) than [1] (occurrence: $38.58 \%$ of languages), yet the former shifted the least in the current study. Typological markedness can, therefore, not fully explain the observed patterns.

Alternatively, the frequency with which consonants occur in English may offer an explanation. Thus, one might expect less commonly occurring sounds to be more unstable and hence, more vulnerable to shifts. However, in studies of English consonant phoneme frequency (e.g., Edwards 1992; Wang and Crawford 1960), /s / is consistently ranked as more frequent than $/ \int /$, yet the former was found to shift in the direction of the less frequent $\left[\int\right]$ in the present study.

Finally, we considered to what extent acoustic distance may be able to account for the observed hierarchy across our three sound pairs. For present purposes, acoustic distance was defined as the mean difference in Hertz in the monolingual control speakers productions for each sound pair. According to this measure, [s-f] exhibited by far the smallest acoustic difference, i.e., approximately $280 \mathrm{~Hz}$, while that for [v-w] and [1-1] was much greater (approximately $780 \mathrm{~Hz}$ and $750 \mathrm{~Hz}$, respectively). Since our findings revealed substantially greater shifts for $[\mathrm{s}]$ than $[\mathrm{w}]$ and $[\mathrm{t}]$, differences in acoustic distance may indeed provide an explanation. In other words, the phonetic proximity of [s] and [J] may have rendered this sound pair more vulnerable to shifts than the two acoustically more distinct sound pairs. As such, the findings of the present study are in line with one of the central tenets of the SLM (Flege 1995; Flege and Bohn 2021): that phonetically similar sounds are more unstable and more likely to be assimilated than dissimilar ones. Future research is needed to explore this issue further and determine the role that the L2 plays in rendering L1 sound contrasts less stable in code-switched settings. 
As for the direction of L2-induced influences, based on findings by Bullock and Toribio (2009), it was hypothesized that L2-induced changes during dual language activation may be more common in segments occurring before (regressive) a switch than in those occurring after a switch (progressive L2-influence). This was, however, not confirmed by our data. Our results showed no significant differences in the L2-induced changes occurring before or after the switch. However, a fair amount of individual variation was observed, with individual speakers who had undergone L1 changes, showing shifts either only under regressive influence, or in both regressive and progressive environments. While we are thus unable to draw firm conclusions, overall, our data suggest no privileged direction of L2-induced changes. Future research is needed that explores this issue on a larger scale and using different methodologies to aid our understanding of the cognitive processes that underpin interaction in bilingual sound systems.

\subsection{Individual Variation and the Role of Predictor Variables}

In general, there was a considerable amount of individual variation, not only in the direction of L2-induced influences, but also between males and females, or in whether or not code-switching resulted in L1 shifts. For instance, while both BIL men and women had a tendency to shift $[\mathrm{w}]$ towards [v] in their code-switched tokens, this was only significant in the male participants and only in sounds that occurred before a switch (i.e., under regressive L2 influence). Similarly, while no significant shift was found for [s] in the codeswitched speech of BIL females, in male speakers, the [s] had shifted in the direction of [J] under both regressive and progressive influences. For [ 1 ], code-switching did not lead to a shift in either males or females. The difference between males and females was also apparent in the individuals who exhibited significant shifts in code-switched speech, where the males clearly outnumbered the females (with 4 males as opposed to 1 female shifting $[\mathrm{w}]$ towards [v] and 11 males versus 2 females shifting [s] towards [ [j]). It may be that adult women (the pattern is less clear in children) are more "experienced" code-switchers, as they are sometimes reported to code-switch more often than men in various social contexts (Alicea 2001; Hafissatou 2020; Wong 2006). Experienced code-switchers, in turn, have been found to exhibit less short-term cross-language phonetic interaction (Šimáčková and Podlipský 2015), which may provide a tentative explanation of the observed shifts between males and females in our study. It may be worth exploring the role of gender in future studies.

The variability observed in our study does not come as a surprise, as variability in the extent to which individuals exhibit changes in L1 speech has been widely documented (e.g., Bergmann et al. 2016; de Leeuw et al. 2012; Major 1992; Mayr et al. 2012; Mennen 2004). While seventeen out of twenty-five participants $(68 \%)$ in our study showed signs of L1 changes during code-switched speech, the remaining eight $(32 \%)$ did not. This means that L1 changes in the context of code-switching are not inevitable, and perhaps these speakers were able to suppress the phonetic interaction that typically occurs in code-switched speech where both languages are maximally activated. In an attempt to explain why some speakers in our study exhibited changes while others did not, we examined whether the variables AoE, LoR, C $+M, C-M$, amount of $L 1$ use, amount of $L 2$ use and $L 2$ proficiency could predict the shift size of sounds produced in code-switched compared to monolingual utterances. The only variable that was found to significantly predict this was amount of L2 use, and it only did so for the sound [w]. That is, speakers who used their L2 more were found to shift their productions of $[\mathrm{w}]$ in code-switched speech toward [v]. While there are no studies on the role of predictor variables in code-switched speech, previous studies on L1 attrition also found an effect of the overall amount of L2 use (Stoehr et al. 2017). In their study, however, the amount of L2 use was inferred from whether the participants were immersed in an L2-speaking environment (and largely limiting L1 use) or not, rather than factored into a regression analysis. While our study found an effect of the overall amount of L2 use, no effect was found for the overall amount of L1 use. Previous studies on the role of overall amount of L1 use in L2-induced phonetic changes in the L1 have shown 
varied effects. While an effect of reduced L1 use was reported in Stoehr et al. (2017; but see our comments above), no effect was found in Hopp and Schmid (2013), and a recent study on phonetic drift also challenges the role of reduced L1 use (Dmitrieva et al. 2020).

Given that our study tested the shifts in L1 speech during code-switching, where both languages are maximally activated, we expected to find an influence of dual language activation similar to the one reported in de Leeuw et al. (2010) and Mayr et al. (2020). We therefore used predictor variables similar to those in de Leeuw et al. (2010), to test whether the type of contact with the L1 (i.e., in settings where language mixing is likely or unlikely to occur) could predict whether a shift in L1 speech would occur, with the expectation that shifts would be more likely when L1 contact involved language mixing. However, we found no effect of either $\mathrm{C}+\mathrm{M}$ (L1 contact in settings where language mixing is likely to occur) nor $\mathrm{C}-\mathrm{M}$ (L1 contact in settings where language mixing is unlikely to occur). One reason for this difference in findings may be that the questions included in the variables $\mathrm{C}+\mathrm{M}$ and C-M in our study did not entirely overlap with those included in de Leeuw et al.'s (2010) study. For instance, our $\mathrm{C}+\mathrm{M}$ variable did not include questions about language used in the church setting, as this was not deemed relevant for our participants. Another reason for this difference in findings may be the fact that de Leeuw et al. (2010) tested the effect of the type of L1 contact on the extent of perceived foreign accent, whereas our study investigated its effect on the produced shifts in L1 sounds. Perceptions of non-nativeness arise from the cumulative effect of a number of characteristics, such as deviations in the realization of vowels, consonants, and prosody (Jilka 2000; Mennen 2004; Ulbrich and Mennen 2016), and are not based on a single acoustic shift in one sound. It may therefore be more difficult to find a link between acoustic changes and predictor variables, particularly as the shifts in our study were relatively small. In fact, acoustic shifts in L1 sounds are bound to be small given the need for the speaker to maintain sufficient phonetic contrast between sound categories both within and across languages. This therefore restricts the size of shifts that are typically observed, with acoustic values often intermediate between the L1 and L2 norms (e.g., Flege 1987; de Leeuw et al. 2013; Major 1992; Mayr et al. 2012). Assimilation effects of this kind were also observed in some of the speakers in our study. This was particularly obvious in the productions of [s], which had shifted in the direction of monolingual [J] in the code-switched utterances of thirteen speakers, some of which showed intermediate values, while others had a complete overlap of [s] and [J]. Interestingly, these thirteen speakers also showed a shift in their production of [J] in non-code-switched utterances, overshooting the values of the MON group. This polarization or dissimilation may result from a need to keep phonetic categories distinct: as their [s] has shifted towards [ [] , the [ [] has moved further away-at least in non-code-switched speech—to keep the two categories maximally distinct. Interestingly, we also found evidence of polarization in the [v] produced by the BIL group, which overshot the values of the MON group (with higher F2 values for [v] in the BIL compared to the MON group). While the occurrence of dissimilation in the [s] productions of the individuals discussed above can be explained by the need to keep categories distinct, this explanation cannot account for the polarization of [v], given that the majority of speakers did not show effects of assimilation for [w]. An alternative explanation would be to assume that the dissimilation is instigated by other instances of dissimilation, such that dissimilation of one sound instigates dissimilation at a system-wide level (see Mayr et al. 2012). However, as the shifts occur in different acoustic parameters and are not observed in all the sounds investigated, this explanation is rather unlikely. In any case, the cross-linguistic interactions between the L1 and L2 system affecting pronunciation are complex and sometimes characterized by unpredictability when the system is reorganizing (de Bot and Larsen-Freeman 2011; Verspoor et al. 2008), and the ad hoc dual language activation in code-switched speech and its dynamic transient nature might add to this complexity. Further research is needed to fully understand this complexity and how it interacts with predictor variables. 


\section{Conclusions}

In conclusion, this study documented dual language activation in the L1 speech of late English-Austrian sequential bilinguals who emigrated to Austria in adulthood. As such, it is one of only few studies to examine the effect of experimentally induced code-switches on the native language of this type of bilingual population, and the first to systematically investigate individual variation and the role of predictor variables in this setting. The results revealed L2-induced shifts in L1 speech production during code-switched contexts, but only for $[\mathrm{w}]$ and [s]. An examination of individual variation showed that such shifts are not inevitable though, since nearly a third of participants did not exhibit a difference in their production of the target sounds across contexts. Unlike previous work (Bullock and Toribio 2009), shifts were found to occur both before and after a code-switch, with a range of patterns observed across participants and groups. Finally, our findings indicated that only amount of L2 use was a significant predictor, and only in the production of one of the sounds examined, i.e., [w].

Although the study significantly extends our understanding of the role of dual language activation on the L1 speech of late sequential bilinguals, it has a number of limitations that should be considered when planning future research. To begin with, our sample size, whilst in line with much of the existing literature on potential L1 attriters, is modest, limiting the generalizability of our findings. In addition, while we carefully considered the design of our experiments, not all aspects had been fully systematized. Thus, the code-switched sentences for [ $\mathrm{t}$ ] only appeared in a progressive environment. Moreover, the phonetic context for [s] words was not balanced across code-switched and non-code-switched settings, which, in turn, may explain why even MON speakers showed no differences in the first spectral moment across vowel and <st $>$ contexts. Finally, since our results revealed differences in L2-induced changes across the sound pairs included, future work is needed that goes beyond these and systematically investigates how dual language activation affects different segmental and suprasegmental areas of pronunciation, and the extent to which they contribute to listeners' perceptions. Studies of this kind will help us shed new light on the complex, dynamic nature of L1 speech patterns in late sequential bilinguals.

Author Contributions: Conceptualization, I.M., R.M., U.R. and S.D.; methodology, I.M., R.M., U.R. and S.D.; formal analysis, U.R.; writing—original draft preparation, I.M. and U.R.; writingreview and editing, I.M., R.M., U.R. and S.D.; visualization, U.R. and S.D.; supervision, I.M.; project administration, I.M.; funding acquisition, I.M. and R.M. All authors have read and agreed to the published version of the manuscript.

Funding: This research was funded by Austrian Science Fund (FWF), grant number P33007-G.

Institutional Review Board Statement: This study was conducted according to the guidelines of the Declaration of Helsinki, and approved by the Institutional Ethics Committee of the University of Graz (protocol code GZ. 39/37/63 ex 2019/20; date of approval: 27 February 2020).

Informed Consent Statement: Informed consent was obtained from all subjects involved in the study.

Data Availability Statement: The data are not publicly available due to ongoing data analyses. Data will be made available upon request from the corresponding authors once all analyses have been completed.

Acknowledgments: We would like to thank the Austrian Science Fund (FWF) for their financial support of this research. We would also like to thank Felix Gschier, Kerstin Endes, Sarah Melker, Matthias Wedenig, and Jiaying Li for their help with proof reading, recruitment and/or data collection, and Klaus Jänsch for his support with WikiSpeech. Finally, we thank Rebecca Clift, Kathleen McCarthy, Paul Foulkes, Ghada Khattab and Bettina Beinhoff for their help in accessing participants in the UK.

Conflicts of Interest: The authors declare no conflict of interest. 


\section{Notes}

Note that de Leeuw et al. (2010) had additional questions about contact with the native language during church visits. As this did not apply to the majority of our participants, we removed those questions from the survey.

2 Sanker et al. (2021) report that acoustic measurements, especially those concerned with spectral properties, are vulnerable to differences in recording equipment and differences in background noise. We dealt with this by using Speaker as a random factor in most of our analyses, so that variability in the recording equipment was coupled with the speakers. In group-wise comparisons, the number of speakers in each group will have partially factored out the variability from differences in recording equipment, because any variability observed is likely to be unsystematic. Moreover, in the individual analyses (in Sections 3.1.3, 3.2.3 and 3.3.3), this additional variability is irrelevant given that we compared code-switched versus non-code-switched speech within the same speaker, and thus, in the same recording setting, as both sets were recorded in a single recording session.

3 We initially planned to analyze $<\mathrm{st}>\left[\int \mathrm{t}-\mathrm{st}\right]$ and $<\mathrm{str}>\left[\int \mathrm{t}(\mathrm{\textrm {s }})-\mathrm{st}(\mathrm{x})\right]$ as separate sound pairs, because of ongoing sound changes in several English varieties (see, e.g., Rutter (2011), Stevens and Harrington (2016) and Lawrence (2000) for American, Australian, New Zealand and British varieties of English, respectively), in which alveolar fricatives become retracted to more post-alveolar ones especially whenever [s] precedes / $\mathrm{t}_{\mathrm{I}} /$. This retraction can also be found for British varieties (Cruttenden 2014), especially those spoken in London (Altendorf 2003) and Colchester (Bass 2009). However, as a pairwise comparison of $<\mathrm{s}(\mathrm{t})>\mathrm{vs}$. $<\mathrm{s}(\mathrm{tr})>\mathrm{showed}$ no significant differences, we decided to pool the two sound pairs to increase statistical power.

4 Note, however, that CS [s] was always taken from contexts with adjacent $/ \mathrm{t} / \mathrm{or} / \mathrm{t} \mathrm{x} /$, whereas non-CS [s] was taken from one word with adjacent $/ \mathrm{t} /<$ study $>$, but otherwise, [s] was adjacent to a vowel ( $<$ seat $>,<$ sick $>,<\operatorname{sinking}>$, $<$ sit $>$, and $<\sin >$ ). We tested (by means of the same statistics as in Section 3.2.2, but with non-CS [s] subdivided into non-CS /sV/ and non-CS /st/) whether the [s] from a / $t$ / context in <study> was different from the [s] tokens from vowel contexts, but we found no significant difference, either in females or males. The only difference to the results reported in the main text was that non-CS [s] from $<$ study $>$ in males showed no significant difference to CS [s] in regressive mode, but it differed significantly from CS [s] in progressive mode $(p<0.05)$ (non-CS $/ \mathrm{sV} /$ differed from CS [s] in both modes). We therefore decided to keep non-CS /s/ as one group.

It could be argued that the observed speech changes that occur during code-switched speech may not result from cross-linguistic interaction, but rather from the elicitation of speech production errors, such as those encountered in tongue twisters (e.g., Frisch and Wright 2002; Pouplier and Hardcastle 2005). However, cross-linguistic influences on the phonetic realization of sounds have also been observed in words that are distant from the switch (Piccinini and Arvaniti 2015) and in consecutive interpreting where bilinguals heard a message in their L1 and then, produced the translation in their L2 (Šimáčková and Podlipský 2015). This suggests that dual language activation is the most likely cause of the observed phonetic changes.

6 Note though that the assertion that no changes were observed in the non-code-switched target sounds was based on a group comparison of the BIL speakers that were observed to have L2-induced changes in code-switched speech. As we did not run an analysis of individual variation (due to concerns about the effects of extrinsic speaker normalization, cf. Section 2.3), we cannot fully exclude the possibility that some individuals may have shown signs of attrition in their non-code-switched speech.

\section{References}

Ahn, Sunyoung, Charles B. Chang, Robert DeKeyser, and Sunyoung Lee-Ellis. 2017. Age effects in first language attrition: Speech perception by Korean-English bilinguals. Language Learning 67: 694-733. [CrossRef]

Alharbi, Amirah, Anouschka Foltz, and Ineke Mennen. Forthcoming. L2 acquisition and L1 attrition of VOTs of voiceless plosives in highly proficient late bilinguals.

Alicea, Evelyn. 2001. Gender differences in the use of language switching and the detachment effect in therapy with Latino/Latina, Spanish/English bilingual clients. Dissertation Abstracts International: Section B: The Sciences and Engineering 62: 2474.

Altendorf, Ulrike. 2003. Estuary English: Levelling at the Interface of RP and South-Eastern British English. Tuebingen: Gunter Narr Verlag.

Antoniou, Mark, Catherine T. Best, Michael D. Tyler, and Christian Kroos. 2011. Inter-language interference in VOT production by L2-dominant bilinguals: Asymmetries in phonetic code-switching. Journal of Phonetics 39: 558-70. [CrossRef]

Balukas, Colleen, and Christian Koops. 2015. Spanish-English bilingual voice onset time in spontaneous code-switching. International Journal of Bilingualism 19: 423-43. [CrossRef]

Bass, Michael. 2009. 'Street or shtreet'? Investigating (str-) palatalisation in Colchester English. Estro: Essex Student Research Online 1: 10-21.

Bates, Douglas, Martin Maechler, Ben Bolker, and Steve Walker. 2015. Fitting Linear Mixed Effects Models Using lme4. Journal of Statistical Software 67: 1-48. [CrossRef]

Bergmann, Christopher, Amber Nota, Simone A. Sprenger, and Monika S. Schmid. 2016. L2 immersion causes non-native-like L1 pronunciation in German attriters. Journal of Phonetics 58: 71-86. [CrossRef]

Boersma, Paul, and David Weenink. 2020. Praat: Doing Phonetics by Computer [Computer Program]. Version 6.1.36. Available online: http:/ / www.praat.org/ (accessed on 12 December 2020).

Bullock, Barbara E., Almeida J. Toribio, Verónica González, and Amanda Dalola. 2006. Language dominance and performance outcomes in bilingual pronunciation. In Proceedings of the 8th Generative Approaches to Second Language Acquisition Conference. Edited by Mary Grantham O'Brien, Christine Shea and John Archibald. Somerville: Cascadilla Press, pp. 9-16. 
Bullock, Barbara E., and Almedia J. Toribio. 2009. Trying to hit a moving target: On the sociophonetics of code-switching. In Interdisciplinary Approaches to Code-Switching. Edited by Ludmila Isurin, Donald Winford and Kees de Bot. Amsterdam: John Benjamins, pp. 189-206. [CrossRef]

Carlisle, Robert S. 1997. The modification of onsets in a markedness relationship: Testing the Interlanguage Structural Conformity Hypothesis. Language Learning 47: 327-61. [CrossRef]

Carlisle, Robert S. 1998. The acquisition of onsets in a markedness relationship: A longitudinal study. Studies in Second Language Acquisition 20: 245-60. [CrossRef]

Carter, Paul G. 2002. Structured Variation in British English Liquids: The Role of Resonance. Ph.D. thesis, University of York, York, UK. Available online: http:/ / ethos.bl.uk/OrderDetails.do?uin=uk.bl.ethos.274527 (accessed on 7 April 2021).

Celata, Chiara, and Jessica Cancila. 2010. Phonological attrition and the perception of geminate consonants in the Lucchese community of San Francisco (CA). International Journal of Bilingualism 14: 185-209. [CrossRef]

Chang, Charles B. 2012. Rapid and Multifaceted Effects of Second-Language Learning on First-Language Speech Production. Journal of Phonetics 40: 249-68. [CrossRef]

Chang, Charles B. 2013. A Novelty Effect in Phonetic Drift of the Native Language. Journal of Phonetics 41: 520-33. [CrossRef]

Chang, Charles B. 2019. Language Change and Linguistic Inquiry in a World of Multicompetence: Sustained Phonetic Drift and Its Implications for Behavioral Linguistic Research. Journal of Phonetics 74: 96-113. [CrossRef]

Childers, Donald G., ed. 1978. Modern Spectrum Analysis. Piscataway: IEEE Computer Society Press, pp. $252-55$.

Cho, Mi-Hui, and Shinsook Lee. 2016. The impact of different L1 and L2 learning experience in the acquisition of L1 phonological processes. Language Sciences 56: 30-44. [CrossRef]

Cruttenden, Alan. 2014. Gimson's Pronunciation of English, 8th ed. Oxford and New York: Routledge. [CrossRef]

de Bot, Kees, and Diane Larsen-Freeman. 2011. Researching Second Language Development from a Dynamic Systems Theory Perspective. In A Dynamic Approach to Second Language Development: Methods and Techniques. Edited by Marjolijn Verspoor, Kees de Bot and Wander Lowie. Amsterdam: John Benjamins, pp. 5-24. [CrossRef]

de Leeuw, Esther, Aurela Tusha, and Monika S. Schmid. 2018a. Individual phonological attrition in Albanian- English late bilinguals. Bilingualism: Language and Cognition 21: 278-95. [CrossRef]

de Leeuw, Esther, Aurela Tusha, Hui Zhao, Kyle Helke, and Alice Greenfield. 2018b. A case of extreme phonetic attrition in the German rhotic. In Mind Matters in SLA. Edited by Clare Wright, Thorsten Piske and Martha Young-Scholten. Bristol: Multilingual Matters, pp. 162-83. [CrossRef]

de Leeuw, Esther, Ineke Mennen, and James M. Scobbie. 2012. Singing a different tune in your native language: First language attrition of prosody. International Journal of Bilingualism 16: 101-16. [CrossRef]

de Leeuw, Esther, Ineke Mennen, and James M. Scobbie. 2013. Dynamic systems, maturational constraints and L1 phonetic attrition. International Journal of Bilingualism 17: 683-700. [CrossRef]

de Leeuw, Esther, Monika S. Schmid, and Ineke Mennen. 2010. The effects of contact on native language pronunciation in an L2 migrant context. Bilingualism: Language and Cognition 13: 33-40. [CrossRef]

de Leeuw, Esther. 2019a. Native speech plasticity in the German-English late bilingual Stefanie Graf: A longitudinal study over four decades. Journal of Phonetics 73: 24-39. [CrossRef]

de Leeuw, Esther. 2019b. Phonetic Attrition. In The Oxford Handbook of Language Attrition. Edited by Monika S. Schmid and Barbara Köpke. Oxford: Oxford University Press, pp. 204-17. [CrossRef]

Dinnsen, Daniel A., Steven B. Chin, Mary Elbert, and Thomas W. Powell. 1990. Some constraints on functionally disordered phonologies: Phonetic inventories and phonotactics. Journal of Speech and Hearing Disorders 33: 28-37. [CrossRef] [PubMed]

Dmitrieva, Olga, Allard Jongman, and Joan A. Sereno. 2010. Phonological neutralization by native and non-native speakers: The case of Russian final devoicing. Journal of Phonetics 38: 483-92. [CrossRef]

Dmitrieva, Olga, Allard Jongman, and Joan A. Sereno. 2020. The effect of instructed second language learning on the acoustic properties of first language speech. Languages 5: 44. [CrossRef]

Dmitrieva, Olga. 2019. Transferring perceptual cue-weighting from second language into first language: Cues to voicing in Russian speakers of English. Journal of Phonetics 73: 128-43. [CrossRef]

Draxler, Christoph, and Klaus Jänsch. 2008. WikiSpeech-A Content Management System for Speech Databases. Paper presented at Interspeech 2008, the Ninth Annual Conference of the International Speech Communication Association, Brisbane, Australia, September 22-26; pp. 1646-49.

Eckman, Fred R. 1977. Markedness and the contrastive analysis hypothesis. Language Learning 27: 315-30. [CrossRef]

Eckman, Fred R. 1991. The Structural Conformity Hypothesis and the acquisition of consonant clusters in the interlanguage of ESL learners. Studies in Second Language Acquisition 13: 23-41. [CrossRef]

Edwards, Harold T. 1992. Applied phonetics: The sounds of American English. San Diego: Singular.

Flege, James E. 1995. Second language speech learning: Theory, findings, and problems. In Speech Perception and Linguistic Experience: Theoretical and Methodological Issues. Edited by Winifred Strange. Timonium: York Press, pp. 233-77.

Flege, James Emil, and James Hillenbrand. 1984. Limits on phonetic accuracy in foreign language speech production. The Journal of the Acoustical Society of America 76: 708-21. [CrossRef]

Flege, James Emil, and Ocke-Schwen Bohn. 2021. The Revised Speech Learning Model (SLM-r). In Second Language Speech Learning: Theoretical and Empirical Progress. Edited by Ratree Wayland. Cambridge: Cambridge University Press, pp. 3-83. [CrossRef] 
Flege, James Emil, and Wieke Eefting. 1987. Cross-language switching in stop consonant perception and production by Dutch speakers of English. Speech Communication 6: 185-202. [CrossRef]

Flege, James Emil. 1987. The production of "new" and "similar" phones in a foreign language: Evidence for the effect of equivalence classification. Journal of Phonetics 15: 47-65. [CrossRef]

Forrest, Karen, Gary Weismer, Paul Milenkovic, and Ronald Dougall. 1988. Statistical analysis of word-initial voiceless obstruents: Preliminary data. Journal of the Acoustical Society of America 84: 115-24. [CrossRef] [PubMed]

Frisch, Stefan A., and Richard Wright. 2002. The phonetics of phonological speech errors: An acoustic analysis of slips of the tongue. Journal of Phonetics 30: 139-62. [CrossRef]

Gargiulo, Chiara, and Mechteld Tronnier. 2020. First language attrition on prosody in a foreign language environment: A speech production study on anaphora resolution. Journal of Monolingual and Bilingual Speech 2: 219-44. [CrossRef]

Goldrick, Matthew, Elin Runnqvist, and Albert Costa. 2014. Language switching makes pronunciation less native-like. Psychological Science 25: 1031-36. [CrossRef] [PubMed]

Green, David W. 1998. Mental control of the bilingual lexico-semantic system. Bilingualism: Language and Cognition 1: 67-81. [CrossRef]

Grosjean, François, and Joanne L. Miller. 1994. Going in and out of languages: An example of bilingual flexibility. Psychological Science 5: 201-6. [CrossRef]

Grosjean, François. 2001. The bilingual's language modes. In One Mind, Two Languages: Bilingual Language Processing. Edited by Janet L. Nicol. Oxford: Blackwell, pp. 1-22.

Guion, Susan G. 2003. The vowel systems of Quichua-Spanish bilinguals: Age of acquisition effects on the mutual influence of the first and second languages. Phonetica 60: 98-128. [CrossRef]

Hafissatou, Kane. 2020. Language Variation: A Case Study of Gender Differences in Wolof-French Codeswitching. International Journal of Language and Linguistics 8: 122-27. [CrossRef]

Haley, Katarina L., Elizabeth Seelinger, Kerry Callahan Mandulak, and David J. Zajac. 2010. Evaluating the spectral distinction between sibilant fricatives through a speaker-centered approach. Journal of Phonetics 38: 548-54. [CrossRef] [PubMed]

Hickey, Raymond. 2020. Persistent features in the English of German speakers. In English in the German-Speaking World. Edited by Raymond Hickey. Cambridge: Cambridge University Press, pp. 208-28. [CrossRef]

Hopp, Holger, and Monika S. Schmid. 2013. Perceived foreign accent in first language attrition and second language acquisition: The impact of age of acquisition and bilingualism. Applied Psycholinguistics 34: 361-94. [CrossRef]

Jilka, Matthias. 2000. The Contribution of Intonation to the Perception of Foreign Accent. Ph.D. thesis, University of Stuttgart, Stuttgart, Germany.

Kartushina, Natalia, Alexis Hervais-Adelman, Ulrich H. Frauenfelder, and Narly Golestani. 2016. Mutual influences between native and non-native vowels in production: Evidence from short-term visual articulatory feedback training. Journal of Phonetics 57: 21-39. [CrossRef]

Kartushina, Natalia, and Clara D. Martin. 2019. Third-language learning affects bilinguals' production in both their native languages: A longitudinal study of dynamic changes in L1, L2 and L3 vowel production. Journal of Phonetics 77: 100920. [CrossRef]

Kisler, Thomas, Uwe D. Reichel, and Florian Schiel. 2017. Multilingual processing of speech via web services. Computer Speech $\mathcal{E}$ Language 45: 326-47. [CrossRef]

Kopečková, Romana, Ulrike Gut, and Christina Golin. 2019. Acquisition of the/v/-/w / contrast by L1 German children and adults. Paper presented at 19th International Congress of Phonetic Sciences, Melbourne, Australia, August 5-9; pp. 3745-49.

Köpke, Barbara, and Monika S. Schmid. 2004. First language attrition: The next phase. In First Language Attrition: Interdisciplinary Perspectives on Methodological Issues. Edited by Monika S. Schmid, Barbara Köpke, Merel Keijzer and Lina Weilemar. Amsterdam: John Benjamins, pp. 1-43. [CrossRef]

Kornder, Lisa, and Ineke Mennen. 2021. Longitudinal developments in bilingual second language acquisition and first language attrition of speech: The case of Arnold Schwarzenegger. Languages 6: 61. [CrossRef]

Kufner, Herbert L. 1971. Kontrastive Phonologie Englisch-Deutsch. Stuttgart: Klett.

Kuznetsova, Alexandra, Per Brockhoff, and Rune Christensen. 2017. lmerTest Package: Tests in Linear Mixed Effects Models. Journal of Statistical Software 82: 1-26. [CrossRef]

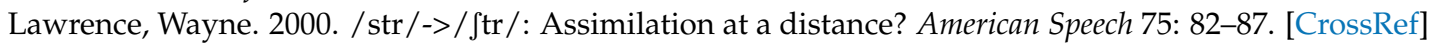

Lehiste, Ilse. 1962. Acoustical Characteristics of Selected English Consonants. The Hague: Mouton.

Lenth, Russell V. 2021. Emmeans: Estimated Marginal Means, aka Least-Squares Means. R Package Version 1.5.4. Available online: https:/ /CRAN.R-project.org/package=emmeans (accessed on 23 November 2020).

López, Verónica González. 2012. Spanish and English word-initial voiceless stop production in code-switched vs. monolingual structures. Second Language Research 28: 243-63. [CrossRef]

Maddieson, Ian, and Kristin Precoda. 1990. Updating UPSID. UCLA Working Papers in Phonetics 74: 104-14. [CrossRef]

Maddieson, Ian. 1984. Patterns of Sounds. Cambridge: Cambridge University Press.

Major, Roy C. 1992. Losing English as a first language. The Modern Language Journal 76: 190-208. [CrossRef]

Major, Roy C. 2010. First language attrition in foreign accent perception. International Journal of Bilingualism 14: 163-83. [CrossRef]

Mayr, Robert, David Sánchez, and Ineke Mennen. 2020. Does Teaching Your Native Language Abroad Increase L1 Attrition of Speech? The Case of Spaniards in the United Kingdom. Languages 5: 41. [CrossRef] 
Mayr, Robert, Sasha Price, and Ineke Mennen. 2012. First language attrition in the speech of Dutch-English bilinguals: The case of monozygotic twin sisters. Bilingualism: Language and Cognition 15: 687-700. [CrossRef]

Mennen, Ineke, and Denise Chousi. 2018. Prosody in first-generation adult immigrants and second-generation heritage-language users: The timing of prenuclear rising accents. In Proceedings of the 9th Speech Prosody Conference. Edited by Katarzyna Klessa, Jolanta Bachan, Agnieszka Wagner, Maciej Karpínski and Daniel Śledziński. Poznan: University of Poznan, pp. 828-32. [CrossRef]

Mennen, Ineke. 2004. Bi-directional interference in the intonation of Dutch speakers of Greek. Journal of Phonetics 32: 543-63. [CrossRef]

Moosmüller, Sylvia, Carolin Schmid, and Julia Brandstätter. 2015. Illustrations of the IPA: Standard Austrian German. Journal of the International Phonetic Association 45: 339-48. [CrossRef]

Moulton, William G. 1962. The Sounds of English and German. Chicago: University of Chicago Press.

Muldner, Kasia, Leah Hoiting, Leyna Sanger, Lev Blumenfeld, and Ida Toivonen. 2019. The phonetics of code-switched vowels. International Journal of Bilingualism 23: 37-52. [CrossRef]

Olson, Daniel J. 2012. The phonetics of insertional code-switching: Suprasegmental analysis and a case for hyper-articulation. Linguistic Approaches to Bilingualism 2: 443-57. [CrossRef]

Olson, Daniel J. 2013. Bilingual language switching and selection at the phonetic level: Asymmetrical transfer in VOT production. Journal of Phonetics 41: 407-20. [CrossRef]

Piccinini, Page, and Amalia Arvaniti. 2015. Voice onset time in Spanish-English spontaneous code-switching. Journal of Phonetics 52: 121-37. [CrossRef]

Pouplier, Marianne, and William Hardcastle. 2005. A re-evaluation of the nature of speech errors in normal and disordered speakers. Phonetica 62: 227-43. [CrossRef]

R Core Team. 2020. R: A Language and Environment for Statistical Computing. Vienna: R Foundation for Statistical Computing, Available online: https: / / www.R-project.org/ (accessed on 17 November 2020).

Rutter, Ben. 2011. Acoustic analysis of a sound change in progress: The consonant cluster /sti / in English. Journal of the International Phonetic Association 41: 27-40. [CrossRef]

Sancier, Michele L., and Carol A. Fowler. 1997. Gestural Drift in a Bilingual Speaker of Brazilian Portuguese and English. Journal of Phonetics 25: 421-36. [CrossRef]

Sanker, Chelsea, Sarah Babinski, Lyn Burns, Marisha Evans, Juhyae Kim, Slater Smith, Natalie Weber, and Claire Bowern. 2021. (Don't) Try This at Home! The Effects of Recording Devices and Software on Phonetic Analysis. Lingbuzz: Lingbuzz/005748. Available online: https:/ / lingbuzz.net/lingbuzz/005748 (accessed on 10 February 2020).

Schmid, Monika S. 2002. First Language Attrition, Use and Maintenance: The Case of German Jews in Anglophone Countries. Amsterdam: John Benjamin. [CrossRef]

Schmid, Monika S. 2011. Language Attrition. New York: Cambridge University Press. [CrossRef]

Šimáčková, Šárka, and Václav J. Podlipský. 2015. Immediate phonetic interference in code-switching and interpreting. Paper presented at 18th International Congress of Phonetic Sciences, Glasgow, UK, August 10-14.

Stevens, Mary, and Jonathan Harrington. 2016. The phonetic origins of /s/-retraction: Acoustic and perceptual evidence from Australian English. Journal of Phonetics 58: 118-34. [CrossRef]

Stoehr, Antje, Titia Benders, Janet G. van Hell, and Paula Fikkert. 2017. Second language attainment and first language attrition: The case of VOT in immersed Dutch-German late bilinguals. Second Language Research 33: 483-518. [CrossRef]

Tobin, Stephen J., Hosung Nam, and Carol A. Fowler. 2017. Phonetic Drift in Spanish-English Bilinguals: Experiment and a Self-Organizing Model. Journal of Phonetics 65: 45-59. [CrossRef]

Ulbrich, Christiane, and Ineke Mennen. 2016. When prosody kicks in: The intricate interplay between segments and prosody in perceptions of foreign accent. International Journal of Bilingualism 20: 522-49. [CrossRef]

Ulbrich, Christiane, and Mikhail Ordin. 2014. Can L2-English influence L1-German? The case of post-vocalic/r/. Journal of Phonetics 45: 26-42. [CrossRef]

Van Hell, Janet G., and Ton Dijkstra. 2002. Foreign language knowledge can influence native language performance in exclusively native contexts. Psychonomic Bulletin and Review 9: 780-89. [CrossRef]

Verspoor, Marjolijn, Wander Lowie, and Marijn van Dijk. 2008. Variability in Second Language Development from a Dynamic Systems Perspective. The Modern Language Journal 92: 214-31. [CrossRef]

Wang, William S.-Y., and John Crawford. 1960. Frequency studies of English consonants. Language and Speech 3: 131-39. [CrossRef]

Watts, Erica, and Yvan Rose. 2020. Markedness and implicational relationships in phonological development: A cross-linguistic investigation. International Journal of Speech-Language Pathology 22: 669-82. [CrossRef] [PubMed]

Winkelmann, Raphael, Jonathan Harrington, and Klaus Jänsch. 2017. EMU-SDMS: Advanced speech database management and analysis in R. Computer Speech \& Language 45: 392-410. [CrossRef]

Winkelmann, Raphael, Klaus Jaensch, Steve Cassidy, and Jonathan Harrington. 2020. emuR: Main Package of the EMU Speech Database Management System. R Package Version 2.1.1. Available online: https://cran.r-project.org/web/packages/emuR/index.html (accessed on 2 October 2020).

Wong, Kwok-Lan Jamie. 2006. Gender and Codemixing in Hong Kong. Honours thesis, The University of Sydney, Sydney, Australia. Available online: https:/ / ses.library.usyd.edu.au/bitstream/handle/2123/1726/wong-jamie-thesis.pdf?sequence=2\& isAllowed $=\mathrm{y}$ (accessed on 19 June 2021). 